\title{
Airborne DOAS limb measurements of tropospheric trace gas profiles: case studies on the profile retrieval of $\mathrm{O}_{4}$ and $\mathrm{BrO}$
}

\author{
C. Prados-Roman ${ }^{1, *}$, A. Butz ${ }^{2, * *}$, T. Deutschmann ${ }^{1}$, M. Dorf ${ }^{1}$, L. Kritten ${ }^{1, * *}$, A. Minikin ${ }^{3}$, U. Platt ${ }^{1}$, H. Schlager ${ }^{3}$, \\ H. Sihler ${ }^{1,4}$, N. Theys ${ }^{5}$, M. Van Roozendael ${ }^{5}$, T. Wagner ${ }^{4}$, and K. Pfeilsticker ${ }^{1}$ \\ ${ }^{1}$ Institute of Environmental Physics, University of Heidelberg, Germany \\ ${ }^{2}$ Netherlands Institute for Space Research - SRON, Utrecht, The Netherlands \\ ${ }^{3}$ Institut für Physik der Atmosphäre, Deutsches Zentrum für Luft- und Raumfahrt (DLR), Oberpfaffenhofen, Germany \\ ${ }^{4}$ Max-Planck-Institute for Chemistry, Mainz, Germany \\ ${ }^{5}$ Belgian Institute for Space Aeronomy - BIRA-IASB, Belgium \\ *now at: Laboratory for Atmospheric and Climate Science (CIAC) CSIC, Toledo, Spain \\ **now at: Institute for Meteorology and Climate Research - Atmospheric Trace Gases and Remote Sensing, \\ Karlsruhe Institute of Technology, Germany \\ ***now at: Institute for Space Sciences, Freie Universität Berlin, Germany
}

Received: 28 July 2010 - Published in Atmos. Meas. Tech. Discuss.: 30 August 2010

Revised: 2 June 2011 - Accepted: 23 June 2011 - Published: 28 June 2011

\begin{abstract}
A novel limb scanning mini-DOAS spectrometer for the detection of $\mathrm{UV} / \mathrm{vis}$ absorbing radicals (e.g., $\mathrm{O}_{3}, \mathrm{BrO}$, IO, HONO) was deployed on the DLR-Falcon (Deutsches Zentrum für Luft- und Raumfahrt) aircraft and tested during the ASTAR 2007 campaign (Arctic Study of Tropospheric Aerosol, Clouds and Radiation) that took place at Svalbard $\left(78^{\circ} \mathrm{N}\right)$ in spring 2007 . Our main objectives during this campaign were to test the instrument, and to perform spectral and profile retrievals of tropospheric trace gases, with particular interest on investigating the distribution of halogen compounds (e.g., $\mathrm{BrO}$ ) during the so-called ozone depletion events (ODEs). In the present work, a new method for the retrieval of vertical profiles of tropospheric trace gases from tropospheric DOAS limb observations is presented. Major challenges arise from modeling the radiative transfer in an aerosol and cloud particle loaded atmosphere, and from overcoming the lack of a priori knowledge of the targeted trace gas vertical distribution (e.g., unknown tropospheric $\mathrm{BrO}$ vertical distribution). Here, those challenges are tackled by a mathematical inversion of tropospheric trace gas profiles using a regularization approach constrained by a retrieved vertical profile of the aerosols extinction coefficient $\mathcal{E}_{\mathcal{M}}$. The validity and limitations of the algorithm are tested with in situ measured $\mathcal{E}_{\mathcal{M}}$, and with an absorber of known vertical profile $\left(\mathrm{O}_{4}\right)$. The method is then used for retrieving vertical
\end{abstract}

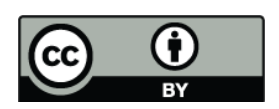

Correspondence to: C. Prados-Roman (cristina.prados@iup.uni-heidelberg.de) profiles of tropospheric $\mathrm{BrO}$. Results indicate that, for aircraft ascent/descent observations, the limit for the $\mathrm{BrO}$ detection is roughly $1.5 \mathrm{pptv}\left(\mathrm{pmol} \mathrm{mol}^{-1}\right.$ ), and the $\mathrm{BrO}$ profiles inferred from the boundary layer up to the upper troposphere and lower stratosphere have around 10 degrees of freedom.

For the ASTAR 2007 deployments during ODEs, the retrieved $\mathrm{BrO}$ vertical profiles consistently indicate high $\mathrm{BrO}$ mixing ratios $(\sim 15 \mathrm{pptv})$ within the boundary layer, low $\mathrm{BrO}$ mixing ratios $(\leq 1.5 \mathrm{pptv})$ in the free troposphere, occasionally enhanced $\mathrm{BrO}$ mixing ratios $(\sim 1.5 \mathrm{pptv})$ in the upper troposphere, and increasing $\mathrm{BrO}$ mixing ratios with altitude in the lowermost stratosphere. These findings agree reasonably well with satellite and balloon-borne soundings of total and partial $\mathrm{BrO}$ atmospheric column densities.

\section{Introduction}

The Differential Optical Absorption Spectroscopy (DOAS) is a well known and established atmospheric measurement technique (Platt and Stutz, 2008). In many applications using scattered skylight, the main challenge of the remote sensing DOAS method lies in retrieving trace gas concentrations from the measured differential slant column densities (dSCDs). Trace gas concentrations are inferred by consecutively probing the air masses at different viewing geometries, and a subsequent mathematical inversion of the whole set of observations (e.g., Rodgers, 2000). In the best case scenario,

Published by Copernicus Publications on behalf of the European Geosciences Union. 
the sampling is arranged so that the pieces of independent information on the multi-dimensional (spatial and temporal) distribution of the targeted species is maximized. In practice however, the degrees of freedom are often limited since the changing viewing geometries are predetermined by movements of the light source (e.g., by celestial light sources), by displacements of the instrument platform (ships, aircrafts, balloons, satellites, etc), by the change of the viewing direction of the light receiving telescope, or by a combination of all of the above. Gathering the information often requires sampling over a large spatial or temporal domain of the atmosphere, in which the radiative transfer (RT) may change considerably as well. The need of dealing with these observational limitations correctly, and of accounting for the atmospheric RT of each individual measurement properly, defines a rather complicated (and in general ill-posed) mathematical inversion problem. Different strategies have been developed to solve these ill-posed inversion problems (e.g., Rodgers, 2000). This paper reports on aircraft-borne limb observations of important trace gases (e.g., tropospheric $\mathrm{BrO}$ ) monitored in a heterogeneously scattering atmosphere (the Arctic spring troposphere). Herein, a dedicated method for the profile retrieval of trace gases constrained by means of measured relative radiances is introduced and validated. In a similar way as in the recently published work of Vlemmix et al. (2010), the observed (relative) radiances are used to describe the scattering processes in the atmosphere during the time of the measurements. Unlike Vlemmix et al. (2010), here not only the total aerosol optical thickness is inferred, but also the vertical profiles of the extinction coefficient $\left(\mathcal{E}_{\mathcal{M}}\right)$ of aerosol and cloud particles (from now on referred to as "aerosols"). The targeted trace gas profile inversion, constrained by the retrieved aerosol $\mathcal{E}_{\mathcal{M}}$, is then addressed with a regularization approach using no a priori knowledge of its vertical distribution (e.g., Phillips, 1962; Rodgers, 2000).

The validity of the novel algorithm is demonstrated for deployments of an optical spectrometer (a mini-DOAS instrument) on the DLR-Falcon aircraft during the ASTAR 2007 campaign. Within the framework of the International Polar Year 2007/2008, and as part of the POLARCAT project ("Polar Study using Aircraft, Remote Sensing, Surface Measurements and Models, of Climate, Chemistry, Aerosols, and Transport"), the ASTAR 2007 campaign aimed at investigations during the Arctic haze season (e.g., Quinn et al., 2007). The campaign was based on Spitsbergen $\left(78^{\circ} \mathrm{N}, 18^{\circ} \mathrm{E}\right)$ and took place during March and April 2007. During this field campaign, target trace gases to be detected from the boundary layer (BL) up to the upper troposphere/lowermost stratosphere (UT/LS) with the mini-DOAS instrument were $\mathrm{O}_{3}$, $\mathrm{NO}_{2}, \mathrm{BrO}, \mathrm{OClO}, \mathrm{IO}, \mathrm{OIO}, \mathrm{HONO}, \mathrm{C}_{2} \mathrm{H}_{2} \mathrm{O}_{2}, \mathrm{CH}_{2} \mathrm{O}, \mathrm{H}_{2} \mathrm{O}$ and $\mathrm{O}_{4}$. Since recent studies point out the relevance of halogens for the tropospheric photochemistry (e.g. von Glasow and Crutzen, 2003), this work primarily focuses on the detection and retrieval of bromine monoxide $(\mathrm{BrO})$. Indeed, reactive halogen compounds (i.e., $\mathrm{RHC}=\mathrm{X}, \mathrm{XO}, \mathrm{X}_{2}, \mathrm{XY}$,
OXO, HOX, $\mathrm{XONO}_{2}, \mathrm{XNO}_{2}$, with $\mathrm{X}, \mathrm{Y}$ as $\mathrm{I}, \mathrm{Br}$ and $\mathrm{Cl}$ ) are known to be key species, e.g., for the oxidation capacity of the troposphere and for the lifetime limitation of other species such as $\mathrm{O}_{3}, \mathrm{HO}_{\mathrm{x}}\left(=\mathrm{H}+\mathrm{OH}+\mathrm{HO}_{2}\right), \mathrm{NO}_{\mathrm{x}}(=$ $\mathrm{NO}+\mathrm{NO}_{2}$ ), hydrocarbons and dimethylsulfide. RHC are also known to be involved in new particle formation (by iodine compounds, e.g., O'Dowd et al., 2002). Moreover, RHC are related to atmospheric mercury depletion events that eventually scavenge $\mathrm{Hg}$ by snow and particles, and deposition of bio-accumulative mercury to the polar ecosystems (e.g., Steffen et al., 2008). Also characteristic (but not unique) of polar regions are the ozone depletion events (ODEs) occurring in the BL in the polar sunrise. These ODEs are linked to halogen activation in auto-catalytic cycles involving sea-salt aerosols (e.g., $\mathrm{Br}^{-}$), and take place over areas covered by first-year sea ice (e.g., Simpson et al., 2007 and references therein). While the horizontal extent of the $\mathrm{BrO}$ associated with young sea ice is fairly well captured by total column satellite measurements (e.g. Richter et al., 1998; Wagner and Platt, 1998; Wagner et al., 2001; Theys et al., 2011), the BrO tropospheric and stratospheric budget is a current issue of discussion (e.g. Salawitch et al., 2010). In fact a more detailed understanding of the distribution of bromine monoxide in the troposphere is missing today. This lack of tropospheric $\mathrm{BrO}$ vertical profile climatology during the polar spring is the motivation for the development of the retrieval method presented herein.

The paper is structured in four main sections. In Sect. 2, all elements of the retrieval algorithm are introduced and described. This includes brief descriptions of (1) the miniDOAS instrument, (2) the measurement technique and the spectral analysis, and (3) the applied inversion methods, i.e., the characterization of scattering events present in the atmosphere via a non-linear inversion of the vertical profile of the $\mathcal{E}_{\mathcal{M}}$, and the regularization of the targeted trace gas vertical profile. Section 3 addresses (1) the rigor of the assumptions needed for the RT modeling, (2) the validation and sensitivity of our method to retrieve $\mathcal{E}_{\mathcal{M}}$ vertical profiles, and (3) the robustness and sensitivity of the profile regularization of tropospheric trace gases, tested with the absorber of known vertical distribution in the troposphere $\mathrm{O}_{4}\left(\mathrm{O}_{2}-\mathrm{O}_{2}\right.$ collisional dimer, e.g., Pfeilsticker et al., 2001). Section 4 presents the inferred $\mathrm{BrO}$ mixing ratio vertical profiles, compares them to other in situ measured trace gases $\left(\mathrm{O}_{3}, \mathrm{CO}\right)$ and to total $\mathrm{BrO}$ column densities measured by satellite, and discusses the results. Finally, Sect. 5 summarizes and concludes the study.

\section{Method}

This section introduces the mini-DOAS instrument deployed during the ASTAR 2007 campaign, the measurements, the spectral analysis and the tropospheric profile retrieval. Furthermore, the theory behind the retrieval algorithm (i.e, the 
nonlinear inversion of the $\mathcal{E}_{\mathcal{M}}$ vertical profile and the regularization of the trace gas profile) is described.

\subsection{Instrument}

The present mini-DOAS instrument uses scattered sunlight measured in limb mode, i.e. skylight received from the horizon for the detection of trace gases such us $\mathrm{O}_{3}, \mathrm{NO}_{2}, \mathrm{BrO}$, OClO, IO, OIO, $\mathrm{HONO}, \mathrm{C}_{2} \mathrm{H}_{2} \mathrm{O}_{2}, \mathrm{CH}_{2} \mathrm{O}, \mathrm{H}_{2} \mathrm{O}$ and $\mathrm{O}_{4}$. The technique has been developed by the Institute of Environmental Physics at the University of Heidelberg (IUP-HD), and validated via many stratospheric balloon flights during the past several years (e.g., Weidner et al., 2005; Kritten et al., 2010).

The novel mini-DOAS instrument deployed during the ASTAR 2007 campaign consists of a housing with two Ocean Optics spectrometers (QE65000/USB2000 for UV/vis) for the detection of skylight in the spectral range of $320-550 \mathrm{~nm}$. In order to assure optical stability, the spectrometers housing is evacuated, vacuum-sealed and temperature stabilized. The QE65000 and USB2000 spectrometers used have spectral resolutions (FWHM) of $0.4 \mathrm{~nm}$ (4.75 pixels) and $0.7 \mathrm{~nm}$ (6.2 pixels), respectively. The small size $\left(483 \times 400 \times 270 \mathrm{~mm}^{3}\right)$, weight $(25 \mathrm{~kg})$ and power consumption $(14 \mathrm{~W})$ make this mini-DOAS a versatile instrument for many measurement platforms. Indeed, since the instrument was built in 2007, the specific instrument has been deployed on the Falcon aircraft, on balloon gondolas (MIPAS, LPMA/DOAS and SALOMON), and on manned (Geophysica) and in future unmanned (Global Hawk) highaltitude aircrafts. In the case of the Falcon aircraft deployment, the two spectrometers, the stepper-motor controller, the computer and the display are integrated into a 19-inch rack inside of the pressurized cabin. Two fiber bundles (for the UV/vis) directed the light from the two telescopes to the spectrometers. The two telescopes are mounted on two stepper-motors located in an aluminum air-tight window with two slits in the left side of the aircraft, exposed to the skylight with a field-of-view of $0.19^{\circ}$ in the vertical and $2.1^{\circ}$ in the horizontal. During the ASTAR 2007 campaign, both telescopes (for the UV/vis channels) were fixed parallel to the ground so the viewing geometry of our measurements could be directly linked to the aircraft attitude (the elevation angle of the telescopes is given by the roll angle of the aircraft). In particular, the data referred to in this work are exclusively related to the measurements collected by the UV channel (320-402 nm), with a temporal resolution of $\sim 10 \mathrm{~s}$, depending on sampling conditions. For further details on the mini-DOAS instrument (e.g., signal-to-noise ratio and detection limit) and on the ASTAR 2007 campaign, the reader is kindly referred to the work of Prados-Roman (2010).

\subsection{Measurement technique and spectral analysis}

During the ASTAR 2007 campaign two sorties, performed on 1 and 8 April 2007, were specially devoted to probe the Arctic atmosphere for halogen activation (e.g., BrO detection) and the development of ODEs over sea ice regions (see Fig. 1a). Here, based on the ozone measurements performed by in situ instrumentation, the threshold of an ODE situation is 45 ppbv (e.g., Ridley et al., 2003).

This work focuses on the detection of $\mathrm{O}_{4}, \mathrm{BrO}$ and the skylight radiances by aircraft-borne limb measurements. In order to render the treatment of the RT simple, we concentrate on observations performed during passages with low-cloud coverage. These passages were selectively chosen based on (1) the inspection of a video recorded with digital camera installed on the Falcon aircraft looking on the direction of the flight, (2) cloud and aerosol in situ measurements and (3) the measured signal-to-noise ratio of the instrument (details given in the work of Prados-Roman, 2010). From those low-cloud coverage scenarios, one ascent performed during the 8 April sortie is exemplary selected for the validation of the retrieval algorithm presented in this work. This passage (marked by the box in Fig. 1) started at around 14:30 UT, while flying over sea ice at $\sim 81^{\circ} \mathrm{N}$ and $7^{\circ} \mathrm{E}$, with northwesterly ground winds of $6 \mathrm{~m} \mathrm{~s}^{-1}$. During the approximately $30 \mathrm{~min}$ of the ascent, the aircraft climbed from around $50 \mathrm{~m}$ of altitude up to $10.5 \mathrm{~km}$, thus probing the Arctic atmosphere from the BL up to the UT/LS.

The DOAS method is applied for the spectral retrieval of $\mathrm{O}_{4}$ and $\mathrm{BrO}$ (see Fig. 1c,d) after all the spectra are corrected for electronic dark current and offset, and all the trace gas cross-sections $\sigma$ are convolved to the spectral resolution of our instrument. Using the WinDOAS software (Fayt and Van Roozendael, 2001), the measured spectra are analyzed with respect to a spectrum measured when the aircraft entered the LS at around 15:10 UT (referred to as reference or Fraunhofer spectrum in Platt and Stutz, 2008). As a result, the differential slant column densities $(d S C D s)$ can be inferred.

The retrieval of the BrO dSCDs presented in Fig. 1c is based on the study of Aliwell et al. (2002). Sensitivity studies performed with the temperature dependent $\mathrm{BrO}$ absorption cross-section (i.e., for $T=298 \mathrm{~K}$ and $228 \mathrm{~K}$, Wilmouth et al., 1999) show non-negligible influence of the temperature on the retrieved $\mathrm{BrO}$ dSCDs in the BL. Indeed, within the BL, the $\mathrm{BrO}$ dSCDs retrieved considering the $\mathrm{BrO}$ cross-section at $228 \mathrm{~K}$ differ by ca. $20 \%$ from the $\mathrm{BrO}$ dSCDs retrieved using the $\mathrm{BrO}$ cross-section at $298 \mathrm{~K}$. In order to take into account the temperature dependence of the retrieved $\mathrm{BrO}$ dSCDs, and considering that our measurements in the BL are performed at a temperature of $\sim 260 \mathrm{~K}$, the measurement vector (see Sect. 2.3.2) given in the trace gas profile inversion consists of an average of the $\mathrm{BrO}$ dSCDs retrieved at $228 \mathrm{~K}$, and those retrieved at $298 \mathrm{~K}$. Noteworthy is that the temperature dependency of the retrieved $\mathrm{BrO}$ dSCDs becomes imperceptible in the UT/LS since the BrO dSCDs retrieved 

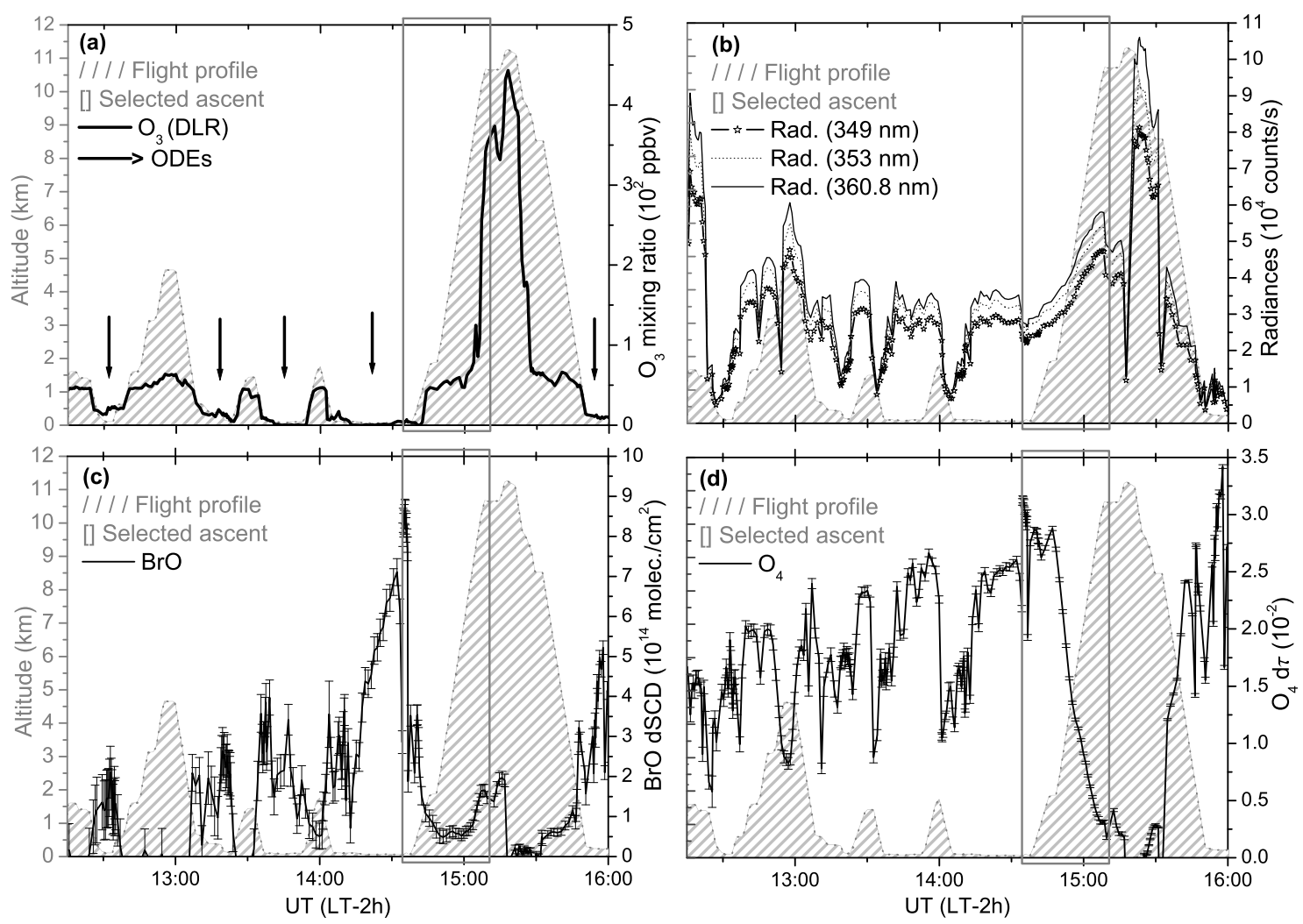

Fig. 1. Measurement flight on 8 April 2007 (72-80 ${ }^{\circ}$ SZA). Panel (a) shows the $\mathrm{O}_{3}$ mixing ratios measured in situ with an UV absorption photometer (DLR). Flight sections within the Arctic BL with ODEs are indicated by arrows. Panels (b)-(d) show, resp., the radiances at different wavelengths, the $\mathrm{BrO}$ dSCDs and the $\mathrm{O}_{4} d \tau$ measured with the UV channel of the mini-DOAS instrument. The tropospheric vertical profiles of the aerosols $\mathcal{E}_{\mathcal{M}}$ and of the trace gases presented in this work are retrieved from data measured during the aircraft ascent starting at around 14:30 UT (box).

at $228 \mathrm{~K}$ fall within the error margins of the $\mathrm{BrO} \mathrm{dSCD}$ retrieved at $298 \mathrm{~K}$.

The UV spectral retrieval of $\mathrm{O}_{4}$ is performed in the 346$366 \mathrm{~nm}$ wavelength interval using the $\mathrm{O}_{4}$ cross-section of Hermans (2002). The interfering species i.e. $\mathrm{O}_{3}$ at $221 \mathrm{~K}$ (Burrows et al., 1999), $\mathrm{NO}_{2}$ at $220 \mathrm{~K}$ (Vandaele et al., 1998) and $\mathrm{BrO}$ at $228 \mathrm{~K}$ (Wilmouth et al., 1999) are also included in the $\mathrm{O}_{4}$ fitting procedure. Results are shown in Fig. 1d. In this work the $\mathrm{O}_{4}$ absorption is used for probing the characterization of the light path in the forward RT model (see Sect. 3.2). In addition, $\mathrm{O}_{4}$ is also used for the self-validation of our trace gas vertical profile retrieval (see Fig. 3.3). Since the vertical distribution of $\mathrm{O}_{4}$ is related to the (squared) oxygen number density $\left[\mathrm{O}_{2}\right], \mathrm{O}_{4}$ differential optical densities $(d \tau=\sigma \cdot \mathrm{dSCD})$ can be derived from the atmospheric temperature and pressure. The $\mathrm{O}_{4}$ absorption cross-section is temperature dependent and its absolute value is not known up to date (Pfeilsticker et al., 2001). The $\mathrm{O}_{4}$ extinction coefficient $\left(\mathcal{E}_{\mathrm{O}_{4}}\right)$ presented in this work is calculated as

$\mathcal{E}_{\mathrm{O}_{4}}=\sigma(T) \times\left[\mathrm{O}_{4}\right]=\sigma \times K_{\text {eq }}(T) \times\left[\mathrm{O}_{2}\right]^{2}$

where $K_{\text {eq }}$ is the equilibrium constant of $\mathrm{O}_{4}$ and, at $360.5 \mathrm{~nm}$ and $296 \mathrm{~K}$, the $\mathrm{O}_{4}$ peak collision pair absorption crosssection $\left(\sigma \cdot K_{\text {eq }}\right)$ has a value of $4.1 \times 10^{-46} \mathrm{~cm}^{5} \mathrm{molec}^{-2}$, known with an accuracy of around $10 \%$ (e.g., Greenblatt et al., 1990; Pfeilsticker et al., 2001).

Skylight radiances are analyzed at $349 \mathrm{~nm}$ (peak crosssection of $\mathrm{BrO}$ absorption band), at $360.8 \mathrm{~nm}$ (peak crosssection of $\mathrm{O}_{4}$ absorption band), and at $353 \mathrm{~nm}$ (negligible $\mathrm{O}_{4}$ and $\mathrm{BrO}$ absorption) aiming at the aerosol retrieval (see Sects. 2.3.1 and 3.2). These radiances are shown in Fig. 1b. Throughout this work the aerosol retrieval is performed at $353 \mathrm{~nm}$ including also the rather small wavelength dependency (around 5\%) in the spectral range of $349-360.8 \mathrm{~nm}$.

\subsection{Profile retrieval}

The retrieval of trace gas vertical profiles requires awareness of the absorption of the compound, as well as of the light path. Since the considered trace gases are optically thin absorbers (e.g., BrO), they should not substantially affect the RT in the considered spectral ranges. Thus, the trace gas retrieval is performed in a two-step process as detailed in Fig. 2. First, the influence of Rayleigh and Mie scattering 


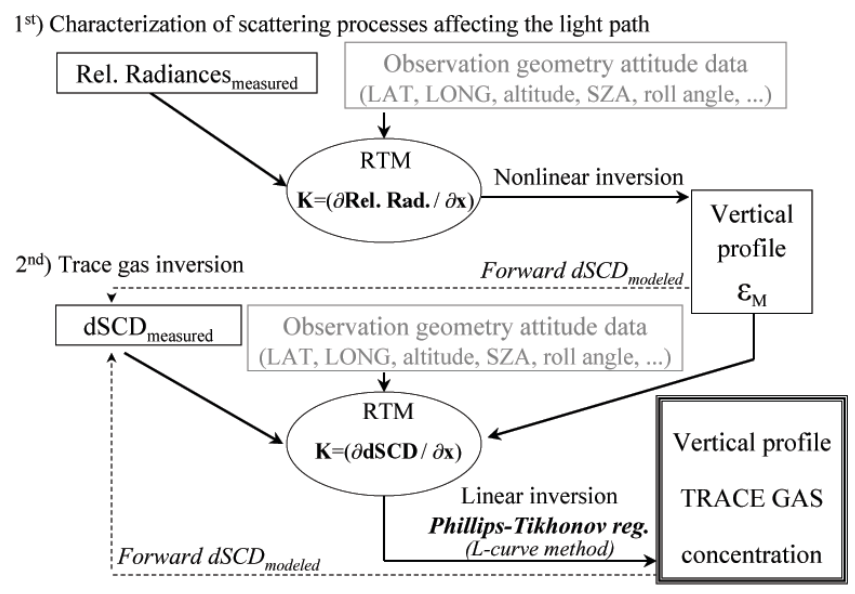

Fig. 2. Summary of the retrieval method in a two-step process: (1) inversion of the vertical distribution of the aerosols extinction coefficient affecting the RT $\left(\mathcal{E}_{\mathcal{M}}\right)$, and (2) inversion of the vertical profile concentration of the trace gas. Sensitivity studies of each step are performed via RT forward modeling (dashed arrows).

affecting the RT during the observations is studied by measuring and modeling Sun normalized radiances at a given wavelength (Sect. 2.3.1). If Mie scattering is found to dominate then, via non-linear inversion from relative radiance measurements, a vertical profile of the aerosol's extinction coefficient $\left(\mathcal{E}_{\mathcal{M}}\right)$ is retrieved on a certain vertical grid. Once the effective light path lengths in the respective layers are modeled with the RT model, the inversion of the targeted trace gas vertical profile from measured dSCDs is performed using the Phillips-Tikhonov approach (Sect. 2.3.2) including the formerly retrieved $\mathcal{E}_{\mathcal{M}}$ profile as a forward parameter in the RT calculations.

\subsubsection{Characterization of scattering events: non-linear inversion of the aerosol's extinction coefficient vertical profile}

A key step of our trace gas retrieval is to infer the light path associated with each of our measurements, and the possible absorption and scattering events influencing our observations. In order to determine the effective light path in our simplified 1-D atmosphere, a vertical profile of the $\mathcal{E}_{\mathcal{M}}$ of aerosols (combination of cloud particles and aerosols) is retrieved.

For the retrieval of the vertical distribution of aerosols in combination with the DOAS technique, the so called " $\mathrm{O}_{4}$ method" is commonly used (e.g., Wagner et al., 2004; Friess et al., 2006). Disadvantages of this method are, however, the restriction to the absorption bands of $\mathrm{O}_{4}$ and, more important, the decreasing sensitivity of the method with altitude (e.g., $\mathrm{O}_{4}$ scale height $\approx 4 \mathrm{~km}$ ). In order to overcome these limitations, our aerosol retrieval approach is not based on $\mathrm{O}_{4}$ but on logarithmic radiance ratios at a given wavelength (for a similar approach see Vlemmix et al., 2010). Since the retrieved $\mathcal{E}_{\mathcal{M}}$ profile is included in the forward RT calculations of the targeted trace gas profile retrieval, the chosen wavelength for the $\mathcal{E}_{\mathcal{M}}$ study is $\lambda=353 \mathrm{~nm}$ (no major trace gas absorption, i.e., optical density smaller than several 0.001 ).

Logarithmic radiance ratios are modeled by a RT model capable of simulating Sun normalized radiances, thus avoiding any absolute calibrating factor $c(\lambda)$ :

$y_{\mathrm{i}}=\ln \left(\frac{L_{\mathrm{i}}(\lambda)}{L_{\mathrm{ref}}(\lambda)}\right)=\ln \left(\frac{c(\lambda) I_{\mathrm{i}}(\lambda)}{c(\lambda) I_{\mathrm{ref}}(\lambda)}\right)=\ln \left(\frac{I_{\mathrm{i}}(\lambda)}{I_{\mathrm{ref}}(\lambda)}\right)$

where $L$ represents the measured radiances, corrected for electronic dark current and offset. The subindex $i$ and ref stand for a certain geometry index and for the reference geometry, respectively.

The RT model used throughout this work is the fully spherical model McArtim ("Monte Carlo Atmospheric Radiative Transfer Inversion Model", Deutschmann, 2008; Deutschmann et al., 2011). Here, the atmospheric RT in the true 3-D atmosphere is simulated in a 1-D modeled atmosphere divided in concentric spherical cells (i.e., vertical grid). The atmospheric conditions in each vertical layer are assumed to remain unaltered and horizontally homogeneous for the time of the measurements. Limitations of this assumption are addressed in Sect. 4.

The cost function of the relative radiances is given by

$$
\begin{aligned}
\chi^{2} & =\left\|\mathbf{S}_{\in}^{-1 / 2}(\boldsymbol{y}-\boldsymbol{F}(\boldsymbol{x}, \boldsymbol{b}))\right\|_{2} \\
& =(\boldsymbol{y}-\boldsymbol{F}(\boldsymbol{x}, \boldsymbol{b}))^{T} \mathbf{S}_{\epsilon}^{-1}(\boldsymbol{y}-\boldsymbol{F}(\boldsymbol{x}, \boldsymbol{b}))
\end{aligned}
$$

where the state vector $x$ is the $\mathcal{E}_{\mathcal{M}}$ vertical profile. In Eq. (3), the measurement vector $\boldsymbol{y}$ is given by the measured Sun normalized radiances, and $\mathbf{F}(\boldsymbol{x}, \boldsymbol{b})$ by the simulated Sun normalized radiances vector, where $\boldsymbol{b}$ represents the auxiliary parameters that will not be retrieved (atmospheric pressure, ground albedo, etc.). The relative error of the measured radiances $L$ is chosen as $4 \%$ in order to account for systematic RT uncertainties such as the Ring effect (e.g., Landgraf et al., 2004; Langford et al., 2007; Wagner et al., 2009a), the used trace gas cross-sections, etc. The diagonal covariance matrix $\mathbf{S}_{\in}$ contains the squared error of the normalized radiances $\boldsymbol{y}$, calculated through error propagation.

Equation (3) is minimized following a standard Levenberg-Marquardt approach, assuring therefore the convergence of $\chi^{2}$ (e.g., Levenberg, 1944; Marquardt, 1963; Press et al., 1986; Rodgers, 2000). In our case, based on e.g. Press et al. (1986), the convergence criteria is fulfilled when (1) $\chi^{2}$ falls into a valley (a decrease of more than $60 \%)$, (2) the relative decrease of $\chi^{2}$ between consecutive iterations is less than $10 \%$, and (3) the step-size is small (a drastic increase of the damping parameter suggests a strong correction to a small pivot). The vertical profile of the $\mathcal{E}_{\mathcal{M}}$ inferred through this method serves to constrain the inversion of tropospheric trace gas vertical profiles detailed in the next section. 


\subsubsection{Trace gas inversion: the regularization method}

The optimal estimation using a priori information of the targeted trace gas is an inversion technique commonly applied for the profile retrieval of trace gases (Rodgers, 2000). Nevertheless, if the a priori covariance $\mathbf{S}_{\mathrm{a}}$ of the targeted trace gas concentration is not known, or if there is no knowledge of the a priori profile $\boldsymbol{x}_{\mathbf{a}}$ (e.g., unknown vertical distribution of $\mathrm{BrO}$ in the troposphere), the regularization method is a more appropriate approach for the retrieval of trace gas profiles (e.g., Hasekamp and Landgraf, 2001). Following the notation given in Rodgers (2000), generally in the regularization method the inverse of the a priori covariance $\mathbf{S}_{\mathrm{a}}^{-1}$ is replaced by a smoothing operator $\mathbf{R}$. The output is then a smoothed version of the true profile where the retrieved absolute values are not compromised.

One of the most widely used regularization methods is the Phillips-Tikhonov approach (Phillips, 1962; Tikhonov, 1963; Tikhonov and Arsenin, 1977). In this method the cost function to be minimized reads

$\left\|\mathbf{S}_{\in}^{-1 / 2}(\boldsymbol{y}-\boldsymbol{F}(\boldsymbol{x}, \boldsymbol{b}))\right\|_{2}+\alpha\|\boldsymbol{L} \boldsymbol{x}\|_{2}$

where $\boldsymbol{y} \in \Re^{m}$ represents the measurement vector and $\mathbf{S}_{\epsilon}$ its covariance matrix. In this case the measurement vector consists of the dSCDs inferred after the DOAS routine (see Sect. 2.2). Since the residual after our spectral retrieval presents no systematic structures, no systematic errors in the spectral retrieval are considered (e.g., Stutz and Platt, 1996). Thus the diagonal of $\mathbf{S}_{\in}$ is built considering the squared of one standard deviation of the DOAS fit error, and the offdiagonal elements of $\mathbf{S}_{\in}$ are set to zero. The expression $\mathbf{F}(\boldsymbol{x}, \boldsymbol{b})$ in Eq. (4) stands for the RT forward model that estimates the effective light path through the atmosphere for each viewing geometry, and therefore provides the modeled dSCDs. The true state (the true vertical profile of the trace gas) is given by $\boldsymbol{x} \in \Re^{n}$, and $\boldsymbol{b}$ are the auxiliary parameters that will not be retrieved (trace gas absorption cross-sections, atmospheric pressure, $\mathcal{E}_{\mathcal{M}}$ profile, etc.). In Eq. (4), $\mathbf{L}$ is the constraint operator which, in our case, is a discrete approximation to the first derivative operator (e.g., Steck, 2002), and $\alpha$ is the regularization parameter giving the strength of the constraint. Therefore, if $\mathbf{R}=\alpha \mathbf{L}^{T} \mathbf{L}$ is the the smoothing operator, the dSCDs cost function to be minimized is

$(\boldsymbol{y}-\boldsymbol{F}(\boldsymbol{x}, \boldsymbol{b}))^{T} \mathbf{S}_{\in}^{-1}(\boldsymbol{y}-\boldsymbol{F}(\boldsymbol{x}, \boldsymbol{b}))+\boldsymbol{x}^{T} \mathbf{R} \boldsymbol{x} \rightarrow \min$

The state vector minimizing Eq. (5) is given by

$\hat{\boldsymbol{x}}_{\text {reg }}=\left(\mathbf{K}^{T} \mathbf{S}_{\in}^{-1} \mathbf{K}+\mathbf{R}\right)^{-1} \mathbf{K}^{T} \mathbf{S}_{\in}^{-1} \boldsymbol{y}$

where $\mathbf{K} \in \mathfrak{\imath}^{m \times n}$ is the Jacobian matrix giving the sensitivity of the (simulated) measurements to the true state $\left(\frac{\partial \mathbf{F}}{\partial x}\right.$, e.g. Deutschmann et al., 2011), therefore providing an insight into the light path.

One of the main challenges of the regularization method is to determine which regularization parameter $\alpha$ provides the most realistic retrieved profile. Although analytical formulas have been suggested where some a priori knowledge $\left(\boldsymbol{x}_{\boldsymbol{a}}\right.$ and $\mathbf{S}_{\mathrm{a}}$ ) is recommended (e.g., Ceccherini, 2005), one of the approaches most widely used to determine $\alpha$ is the L-curve method (e.g., Hansen, 1992; Steck, 2002). In this work, $\alpha$ is defined by the graphical approach of the L-curve, cross-checked with the numerical approach of the maximum curvature (e.g., Hansen, 2007). The goal is indeed to keep a balance between the applied constraint, and the information content provided by the averaging kernel matrix given by

$\mathbf{A}=\left(\mathbf{K}^{T} \mathbf{S}_{\epsilon}^{-1} \mathbf{K}+\mathbf{R}\right)^{-1} \mathbf{K}^{T} \mathbf{S}_{\epsilon}^{-1} \mathbf{K}$

Following the notation in Rodgers (2000), if there is no nullspace of $\mathbf{K}$, then the aimed profile $\hat{\boldsymbol{x}}$ is in fact the regularized profile $\hat{\boldsymbol{x}}_{\text {reg }}$ from Eq. (6). Thus, the retrieved profile $\left(\hat{\boldsymbol{x}}_{\text {reg }}\right)$ is the sum of the true profile smoothed by the averaging kernel matrix and the measurement error, i.e., $\hat{\boldsymbol{x}}_{\text {reg }}=\mathbf{A} \boldsymbol{x}+\boldsymbol{e}$ (e.g., Hasekamp and Landgraf, 2001). The quality of the retrieval is therefore described by the difference between the retrieved state and the true state (Rodgers, 2000):

$\hat{\boldsymbol{x}}_{\text {reg }}-\mathbf{A} \boldsymbol{x}=\boldsymbol{e}_{\text {noise }}+\boldsymbol{e}_{\text {frw }}$

where $\boldsymbol{e}_{\text {noise }}$ represents the retrieval noise. On the other hand, $\boldsymbol{e}_{\text {frw }}$ symbolizes the error in the forward model $\boldsymbol{F}(\boldsymbol{x}, \boldsymbol{b})$. This error comprises the errors in the forward model approximation, and the uncertainties of each of the forward model parameters $\boldsymbol{b}$. As demonstrated through its validation with measurements and other RT models (Deutschmann et al., 2011), the McArtim RT model provides a fair representation of the true atmosphere. Thus, the errors in the forward model approximation are assumed negligible. In the following, $\boldsymbol{e}_{\text {frw }}$ stands for the error in each of the forward model parameters. This $\boldsymbol{e}_{\mathrm{frw}}$ is not straight forward to calculate if the true state is unknown, or if the sensitivity of the RT forward model $\mathbf{F}$ to $\boldsymbol{b}$ (i.e., $\mathbf{K}_{\mathbf{b}}=\frac{\partial \mathbf{F}}{\partial \boldsymbol{b}}$ ) is non linear (e.g., if $\boldsymbol{b}$ is the $\mathcal{E}_{\mathcal{M}}$ profile). The $\boldsymbol{e}_{\text {frw }}$ can in fact be understood as a light path miscalculation and, as shown in the following sections, should not be neglected when simplifying a 3-D (plus time) atmosphere into 1-D. Indeed, as recently argued in Leitão et al. (2010) and Vlemmix et al. (2010), the trace gas retrieval can be improved (its error decreased) if the uncertainty of each forward model parameter is minimized.

\section{Test of the algorithm of the tropospheric trace gas profile retrieval}

In this section the different retrieval steps (see Fig. 2) are applied for measurements performed during the aircraft ascent indicated with a box in Fig. 1 (starting at 14:30 UT). In addition, limitations and error sources of the algorithm are analyzed. Section 3.1 studies the error contribution of different forward parameters $\boldsymbol{b}$ to the RT model, while Sect. 3.2 focuses on the aerosol $\mathcal{E}_{\mathcal{M}}$ profile retrieval. Once an effective 
aerosol $\mathcal{E}_{\mathcal{M}}$ vertical profile is inferred and included in the RT model, the trace gas profile inversion is validated by comparison of regularized and calculated $\mathrm{O}_{4}$ as shown in Sect. 3.3.

\subsection{Analysis of the forward parameters for the radiative transfer modeling}

Optical remote sensing of atmospheric parameters is often hindered by the complexity of the RT in the troposphere. In fact, one of the reasons for selecting the particular aircraft ascent for a more detailed study is the fact that it appears as the simplest RT scenario from the whole flight.

Noteworthy is that, since RT input data may largely suffer from the improper knowledge of their 3-D distribution, here the RT modeling and the inferred quantities (relative radiances and $d \tau$ ) are regarded as an approximation for a more complex reality. Since no further means are available to reconstruct the latter, sensitivity studies are undertaken in order to learn more how uncertainties in the assumptions may propagate into the final result.

In this work some of the important parameters for the RT modeling are (a) taken from in situ instruments deployed on the aircraft, (b) estimated, and (c) inferred from our measurements (i.e., aerosols extinction coefficient $\mathcal{E}_{\mathcal{M}}$ ). This section details (a) and (b) RT forward parameters, while Sect. 3.2 focuses on (c) and the aerosol optical properties affecting the RT.

(a) Physical properties of the atmosphere such as the temperature, pressure, humidity are taken from data collected by the Falcon aircraft basic instrumentation. $\mathrm{O}_{3}$ mixing ratios were measured by the in situ UV absorption photometer (DLR) also on board the Falcon aircraft. Since in the considered wavelength range $\mathrm{O}_{3}$ is only weakly absorbing, spatial variations of the $\mathrm{O}_{3}$ concentration may only weakly influence the RT and thus are not further considered.

(b) The aircraft ascent considered here began at $81^{\circ} \mathrm{N}$, $7^{\circ} \mathrm{E}$ (14:30 UT), flying over sea ice. Sensitivity studies (see Fig. 3, left) indicate that uncertainties of the ground albedo can lead to a rather large relative error $(\sim 30 \%)$ in the RT forward model. However, in this work the ground albedo is inferred with the assistance of an albedometer measurement platform and of the video of the digital camera. The albedometer was aboard the AWI Dornier-228 Polar 2 aircraft that was also deployed during the ASTAR 2007 campaign, and performed measurements of the albedo of sea ice, snow and open water (Ehrlich, 2009). Measurements from the albedometer reported a sea ice albedo of $79 \%$ in the UV-A spectral range. In addition, visual inspection of the recorded movie assisted us to improve our knowledge of the (radiative) ground conditions. As shown in the movie, during the 30 min of the aircraft ascent, the Falcon flew most of the time over closed sea ice, but also over some leads covered by thin ice, and snow covered glacier. Hence, for the RT model of this passage and based on the Falcon's video inspection, a surface albedo of $79 \%$ with an uncertainty of $20 \%$ is considered.

\subsection{Study of the vertical profile retrieval of the aerosol extinction coefficient}

Key parameters for the tropospheric RT are the abundance of aerosol and cloud particles. In general, images from the camera confirmed the (radiative) complexity of the atmosphere during the ASTAR 2007 campaign. Large horizontal surface albedo gradients and/or heterogeneous cloud and particle layers were present during most of the campaign, thus, potentially introducing large uncertainties into the RT. In fact, sensitivity studies show that, for the particular passage of the 8 April deployment studied herein, the aerosol $\mathcal{E}_{\mathcal{M}}$ uncertainty could contribute with more than $40 \%$ of the forward model parameter error (see Fig. 3, right). Accordingly, the most challenging parameter to define for the RT model of each case study appears to be the aerosol and cloud particles.

A summary of the aerosol number densities measured by the in situ instruments in the course of the 8 April 2007 sortie is presented in Fig. 4. During that flight, the haze was not dense in the Arctic atmosphere. However, different aerosol layers were sampled. In situ measurements showed that some pollution (particles and $\mathrm{SO}_{2}$ ) was contained in the $\mathrm{BL}$ which, in general, was characterized by relatively high relative humidity (causing some haze particles, and occasionally some clouds). Another thin pollution layer was observed at $4.5 \mathrm{~km}$ altitude, but only during part of the flight segment just before the ascent sequence started. In the UT/LS, enhanced aerosol concentrations were also observed (at around 15:15 UT). This layer appeared during aircraft ascent and descent at different altitudes ( 8 and $9.5 \mathrm{~km}$ ), suggesting its spatial heterogeneity.

The video of the selected passage of the 8 April sortie shows an overall cloud free atmosphere, and a fairly good visibility. However, some aerosol layers were crossed as reported by two aerosol spectrometer probes deployed by DLR on the Falcon aircraft. These probes were a Passive Cavity Aerosol Spectrometer Probe (PCASP-100X which detected aerosols in a size range of $\sim 0.15-1 \mu \mathrm{m}$ ), and a Forward Scattering Spectrometer Probe (FSSP-300, which monitored the aerosols and cloud particle in the size range $\sim 0.4-20 \mu \mathrm{m}$ ).

The aerosol optical properties affecting the RT at a given wavelength are the phase function (characterized by an asymmetry parameter $g$ ), the single scattering albedo $\left(\varpi_{0}\right)$ and the extinction coefficient $\left(\mathcal{E}_{\mathcal{M}}\right)$. Aiming for a qualitative comparison, a vertical profile of the $\mathcal{E}_{\mathcal{M}}$ is inferred from (1) our optical remote sensing measurements (referred to as IUP-HD $\mathcal{E}_{\mathcal{M}}$ ), and (2) the in situ measured aerosol data (referred to as DLR $\mathcal{E}_{\mathcal{M}}$ ). Details for each retrieval case are as follows:

(1) Proceeding as detailed in Sect. 2.3.1, IUP-HD $\mathcal{E}_{\mathcal{M}}$ is inferred from the (relative) radiances at $353 \mathrm{~nm}$ measured 

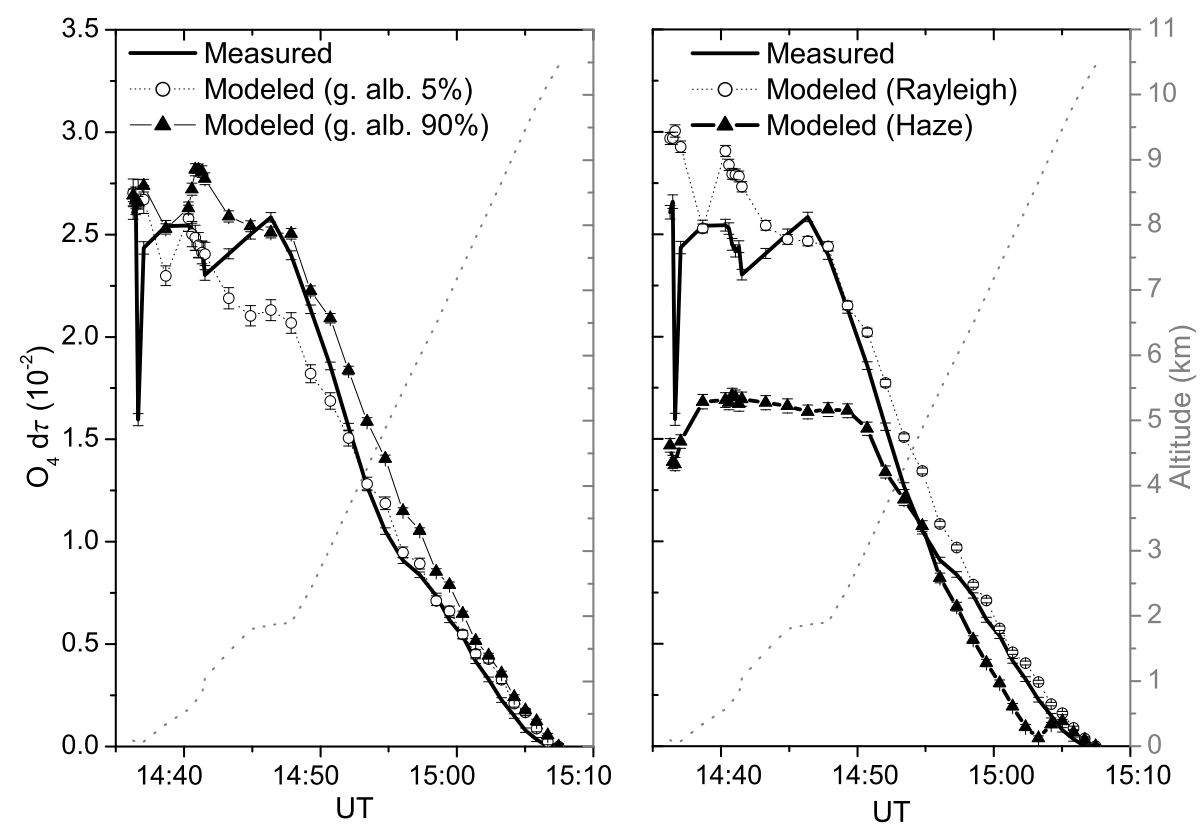

Fig. 3. Influence of forward parameters in the RT model of a known trace gas $\left(\mathrm{O}_{4}\right)$. Left: influence of the ground albedo, comparing the forward modeled $\mathrm{O}_{4} d \tau$ if a ground albedo of $5 \%$ (ocean) and $90 \%$ (snow) are considered in the forward RT model. Right: influence of the $\mathcal{E}_{\mathcal{M}}$ vertical profile, comparing a Rayleigh atmosphere with a rather strong haze situation $\left(\mathcal{E}_{\mathcal{M}}=0.1 \mathrm{~km}^{-1}\right)$ throughout the whole troposphere (79\% ground albedo).

during the ascent starting at 14:30 UT. Aerosol optical parameters considered for that retrieval are the phase function, herein simplified as Henyey-Greenstein's (HenyeyGreenstein, 1941) with $g=0.7$, and $\varpi_{0}=99 \%$. These assumptions are based on measurements of microphysical and radiative aerosol properties performed during the ASTAR 2007 (e.g., Ehrlich et al., 2008; Lampert et al., 2009).

(2) The DLR $\mathcal{E}_{\mathcal{M}}$ from the PCASP-100X and FSSP300 measurements is determined during a number of constant level flight legs (e.g., Weinzierl et al., 2009). For this, averaged particle size distributions are derived assuming a refractive index of an aged ammonium sulfate type of aerosol. In addition, absorption by particles in the tropospheric aerosol column is assumed to be negligible (i.e., $1.54+0.0 i$ is assumed). The scattering (extinction) coefficient is then determined using a Mie model assuming spherical particles. A complete time series (or vertical profile) of scattering/extinction coefficients along the flight is constructed from the aerosol surface area concentrations following from the DLR probes measurements, using the average ratio of scattering coefficient and surface area density in the constant altitude flight legs. Three vertical profile scenarios are obtained: (a) a clean case scenario representing the lowest concentrations per altitude bin over the entire flight, (b) a case for the particular ascent profile flown at around 14:30 UT, and (c) a case scenario representing the few pollution layers found during the flight. In the DLR $\mathcal{E}_{\mathcal{M}}$ retrieval major uncertainties are introduced with the assumptions of refractive index and particle sphericity, which are probably smaller than the variability of atmospheric conditions during the flight. These uncertainties are not further discussed since this exercise only aims for a qualitative comparison of IUP$\operatorname{HD} \mathcal{E}_{\mathcal{M}}$ and DLR $\mathcal{E}_{\mathcal{M}}$.

Inferred $\mathcal{E}_{\mathcal{M}}$ vertical profiles (1) and (2a-c) are compared in Fig. 5, where the vertical resolution of the in situ data has been adopted to the rather coarse resolution of the RT model. As seen in Fig. 5, IUP-HD $\mathcal{E}_{\mathcal{M}}$ tends to a rather clean scenario above the first $500 \mathrm{~m}$ up to the UT/LS. In fact, below $6 \mathrm{~km}$ altitude, IUP-HD $\mathcal{E}_{\mathcal{M}}$ points to an aerosol load even lower than the "cleanest" in situ measured values.

In order to investigate likely causes for these differences and their consequences for the 14:30 UT $\mathcal{E}_{\mathcal{M}}$ inferred profiles (see Fig. 5), sensitivity tests are performed for different parameters.

The most sensitive parameter for the RT in the BL appears to be the ground albedo. By analyzing Fig. 5, if a $20 \%$ uncertainty of the ground albedo is assumed, the inferred IUP-HD $\mathcal{E}_{\mathcal{M}}$ vertical profile shows an averaged $200 \%$ relative error in the very first layers of the BL (see pink shadow). Nevertheless, as seen in the figure, uncertainties in the ground albedo do not cover the differences between both $\mathcal{E}_{\mathcal{M}}$ profiles.

Sensitivity studies indicate also that, for the selected spectral range (349-360.8 nm), the inferred $\mathcal{E}_{\mathcal{M}}$ may only weakly depend on wavelength (by less than $5 \%$ ).

Assumptions regarding optical properties of the aerosol particles may also cause the differences. The IUP-HD $\mathcal{E}_{\mathcal{M}}$ 


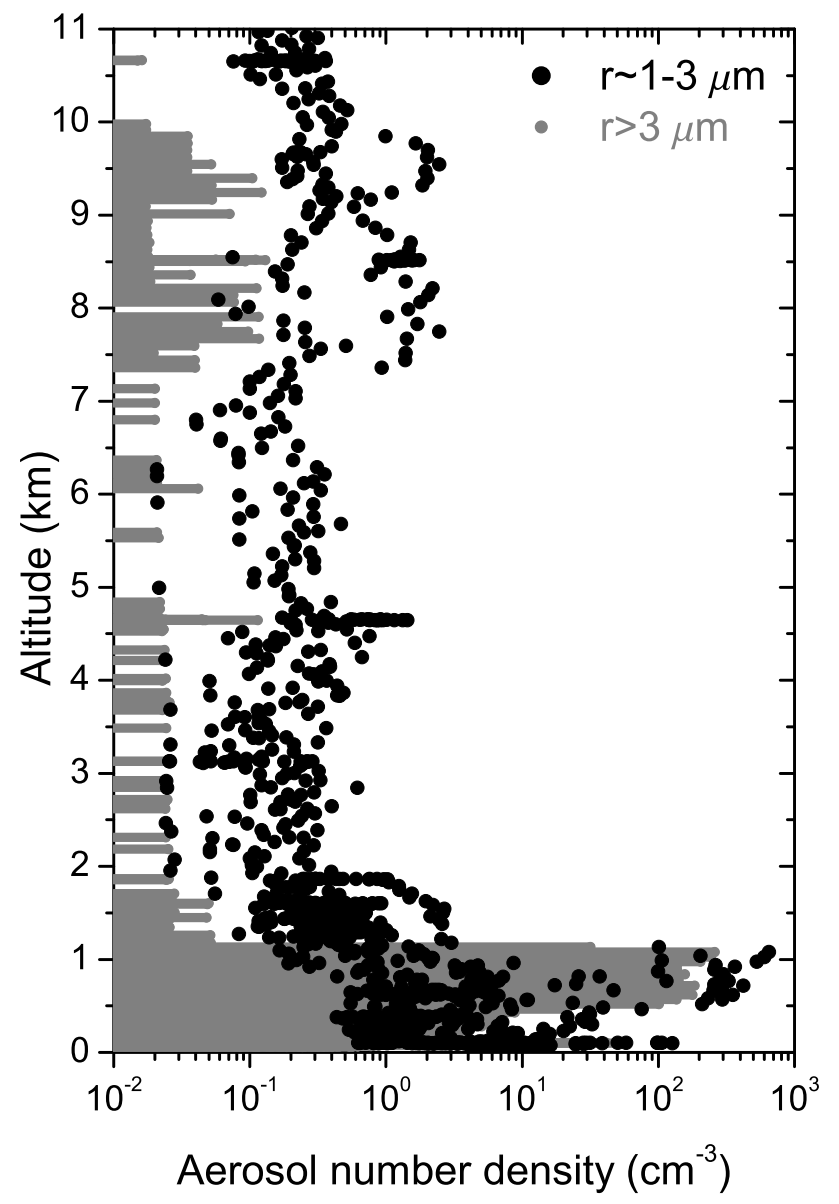

(DLR)

Fig. 4. Vertical profile of coarse mode aerosol number densities (for different particles) measured in situ during the entire 8 April 2007 flight excluding the first and last 20 min of flight close to Longyearbyen airport.

represents an effective extinction coefficient profile constrained to one single type of aerosol (optically described by $g=0.7$ and $\varpi_{0}=99 \%$ ). Conversely, the in situ probes collect data from (optically) different aerosol types that likely coexist in the atmosphere. The single scattering albedo considered in both approaches differs in only $1 \%$. Thus $\varpi_{0}$ is not considered the optical parameter directing the differences between IUP-HD and DLR $\mathcal{E}_{\mathcal{M}}$. On the other hand, sensitivity studies (Fig. 6) indicate that modeling the relative radiances considering DLR $\mathcal{E}_{\mathcal{M}}$ in the RT model, leads to a better agreement with measurements if different values for the asymmetry parameter are allowed at different altitudes.

Bearing all these considerations in mind, a quantitative comparison of the $\mathcal{E}_{\mathcal{M}}$ profiles inferred from both approaches should be regarded with caution. Furthermore, the uncertainties afore mentioned may also indicate the restriction of our aerosol inversion. If the retrieval was not limited by the information content of the measurements, a more de-

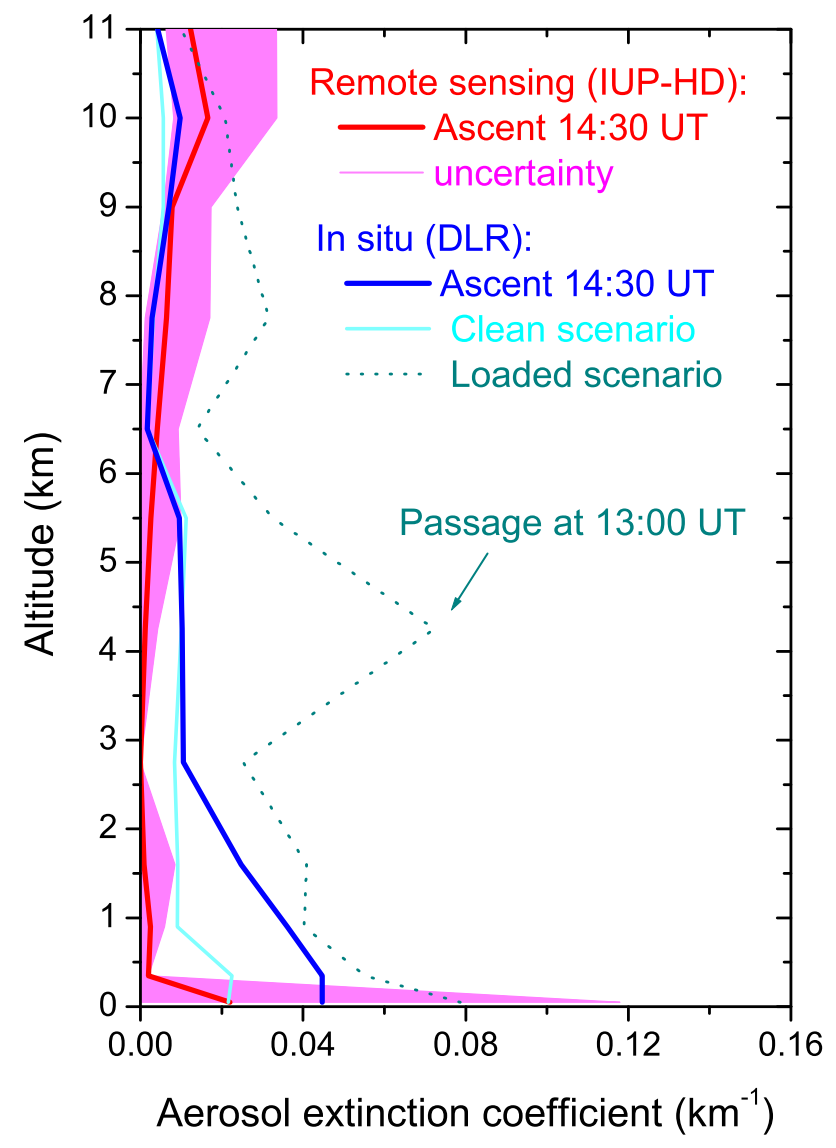

Fig. 5. Vertical profiles of remotely sensed and in situ measured aerosol extinction coefficients $\mathcal{E}_{\mathcal{M}}$ (8 April 2007 sortie). In red, the IUP-HD $\mathcal{E}_{\mathcal{M}}$ retrieved at $353 \mathrm{~nm}$ from measurements performed during the ascent at 14:30 UT is presented (79\% ground albedo, $g=0.7)$. The pink shadow covers wavelength $(349-360.8 \mathrm{~nm})$ and ground albedo uncertainties of IUP-HD $\mathcal{E}_{\mathcal{M}}$. The profiles derived (at $349 \mathrm{~nm}$ ) from the in situ data correspond to the ascent at 14:30 UT (dark blue), and to a clean (cyan) and aerosol loaded case scenario (dashed line) measured during the 8 April 2007 flight.

tailed remote sensed characterization of the aerosol optical properties could be performed, e.g., by an aerosol $\mathcal{E}_{\mathcal{M}}$ inversion not constrained to one type of aerosol, by taking into account possible 3-D effects, by analyzing the rotational Raman scattering (Ring effect, e.g., Wagner et al., 2009b), and by including the polarization of light in the algorithm (e.g., Emde et al., 2010). Moreover, the retrieval of aerosols from measured relative radiances may also be combined with $\mathrm{O}_{4}$ optical density measurements to gather more information of the optical properties of aerosols in the lower troposphere. Nevertheless the information content limits the retrieval and, therefore, such a detailed characterization of aerosols is out of the scope of this work.

Since a self-consistent treatment of the RT is required throughout each of the steps of the retrieval algorithm, Fig. 6 also indicates the limitation of using DLR $\mathcal{E}_{\mathcal{M}}$ as a RT 

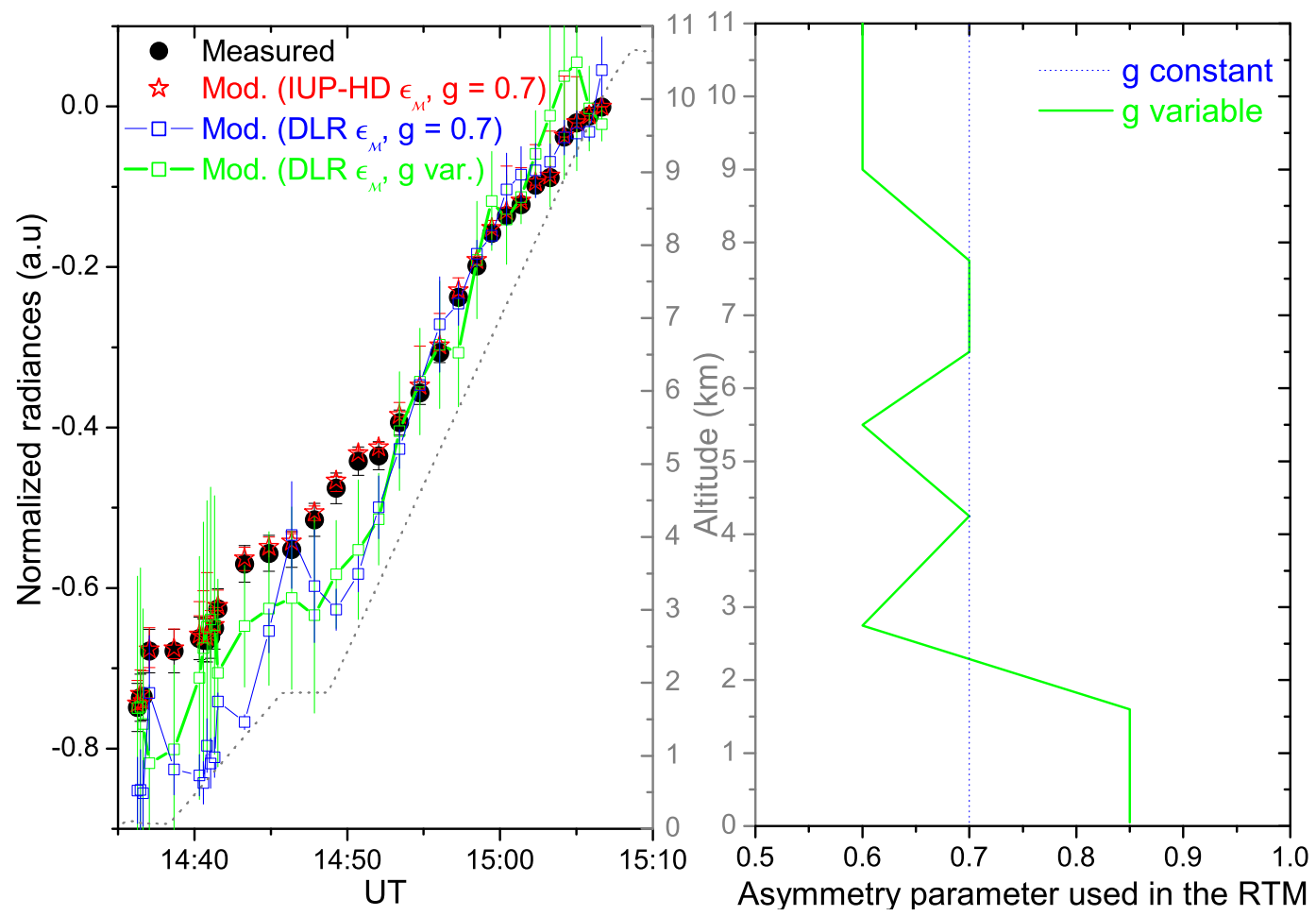

Fig. 6. (Left) Sun normalized radiances measured and modeled during the 14:30 UT ascent (the dotted line represents the flight track). Measured radiances (at $353 \mathrm{~nm}$ ) are shown in black. At $353 \mathrm{~nm}$ and $79 \%$ ground albedo, radiances are modeled considering different $\mathcal{E}_{\mathcal{M}}$ (refer to Fig. 5) and asymmetry parameter scenarios. Red: IUP-HD $\mathcal{E}_{\mathcal{M}}$ with $g=0.7$. Blue: DLR $\mathcal{E}_{\mathcal{M}}$ with $g=0.7$. Green: DLR $\mathcal{E}_{\mathcal{M}}$ with variable $g$. Error bars of all modeled radiances include their wavelength dependency (349-360.8 nm). In addition, a ground albedo uncertainty of $20 \%$ is considered for the DLR radiances. (Right) Profiles of the aerosol asymmetry parameter considered for the RT studies ( $g$ within the range of $0.6-0.85$ as reported for the Arctic, e.g., Lampert et al., 2009).

forward parameter for the inversion of the trace gas profiles (see also Fig. 7, center). Hence, the inferred IUP-HD $\mathcal{E}_{\mathcal{M}}$ profile (constrained to a constant $g$ and $\varpi_{0}$ ) should be regarded as an effective 1-D aerosol extinction profile describing the Mie scattering processes in the 1-D atmosphere. The quality of the characterization of the RT with this approach is validated in the following section.

\subsection{Self-consistency of the retrieval of the tropospheric trace gas vertical profile: $\mathrm{O}_{4}$ regularization}

One of the first steps in our trace gas retrieval method is to choose an atmospheric vertical grid that fits the information content of the measurements. Considering the speed of the aircraft and the typical integration times of our spectra ( $\sim 10 \mathrm{~s}$ ) during the aircraft ascent of interest (see Fig. 1), diverse studies on the altitude grid and the information content of the measurements suggest that a finer grid than the one used in this work (11 layers) does not improve the retrieval but might, however, result in misinterpretation of the measured data at a given layer (depending also on the regularization strength $\alpha$ ).
Following Eq. (6) and using the L-curve criterion to define the regularization parameter $\alpha$ (see Sect. 2.3), the inversion of the $\mathrm{O}_{4}$ extinction coefficient $\left(\mathcal{E}_{\mathrm{O}_{4}}\right)$ vertical profile constrained by the inferred IUP-HD $\mathcal{E}_{\mathcal{M}}$ vertical profile (Fig. 5) is performed. Figure 7 characterizes the $\mathcal{E}_{\mathrm{O}_{4}}$ profile retrieval at $360.8 \mathrm{~nm}$. As shown by its kernel matrix $\mathbf{A}$ (Fig. 7, left), roughly 8 degrees of freedom are obtained in the retrieval of $\boldsymbol{x}_{\text {reg. }}$. Since A gives the sensitivity of the retrieved profile to the true state, an averaging kernel smaller than unity indicates the limitation of the measurements to provide fully independent information of the true state $\boldsymbol{x}$. Therefore, the effective null-space contribution is not negligible. Since $\boldsymbol{x}_{\mathrm{reg}}=\mathbf{A} \boldsymbol{x}$ +error and the true $\mathcal{E}_{\mathrm{O}_{4}}$ state $(\boldsymbol{x})$ is given by Eq. (1), the retrieval error can be estimated. Figure 7 (center) shows $\boldsymbol{x}$ (blue), Ax (red) and $\boldsymbol{x}_{\text {reg }}$ (and covariance, black) for the retrieval of the $\mathrm{O}_{4}$ extinction coefficient profile using the aerosol IUP-HD $\mathcal{E}_{\mathcal{M}}$ as a forward parameter in the RT model. For comparative purposes, Fig. 7 (center) also shows (in green) the regularized $\mathcal{E}_{\mathrm{O}_{4}}$ profile constrained by the $\mathcal{E}_{\mathcal{M}}$ profile as inferred from aerosol concentrations in situ measured (in dark blue in Fig. 5). Figure 7 (right) illustrates the relative error of the $\mathcal{E}_{\mathrm{O}_{4}}$ retrieval (constrained by IUP-HD $\mathcal{E}_{\mathcal{M}}$ profile). In the troposphere (up to $8.5 \mathrm{~km}$ ), 

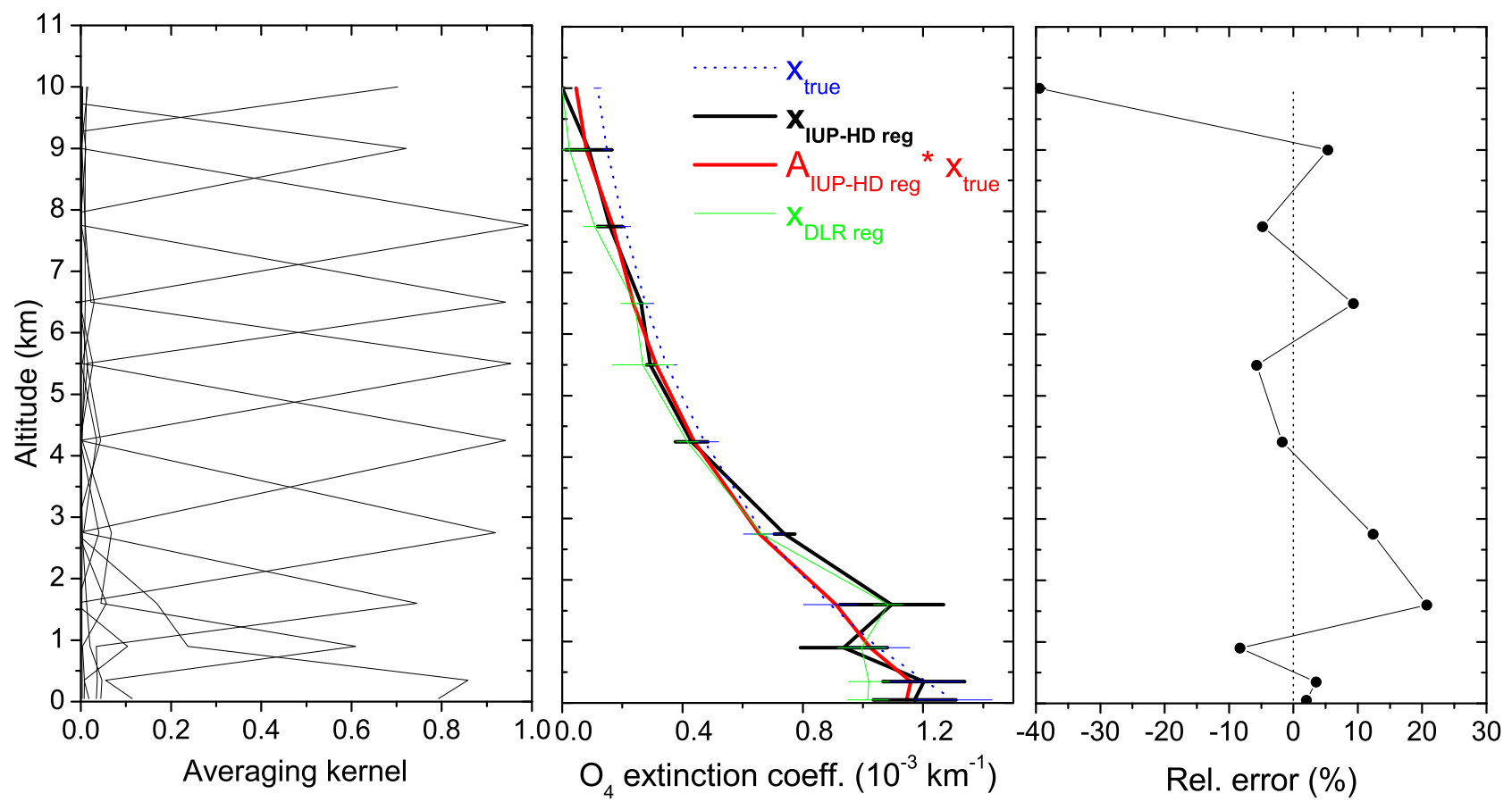

Fig. 7. Retrieval of the vertical distribution of the $\mathrm{O}_{4}$ extinction coefficient $\left(\mathcal{E}_{\mathrm{O}_{4}}\right)$. Left: Averaging kernels showing $\sim 8$ degrees of freedom. Center: The $\mathcal{E}_{\mathrm{O}_{4}}$ true state is shown in blue (considering $10 \%$ error). $\boldsymbol{X}_{\mathrm{IUP}-\mathrm{HD}}$ reg (in black) is the regularized $\mathcal{E}_{\mathrm{O}_{4}}$ profile if the IUP-HD $\mathcal{E}_{\mathcal{M}}$ profile (see Fig. 5) is included in the RT model (the error bars include the retrieval noise and the effect of uncertainties of the ground albedo and the aerosol load). The contribution of the true state to the row space (IUP-HD reg) is shown in red. For comparison purposes,

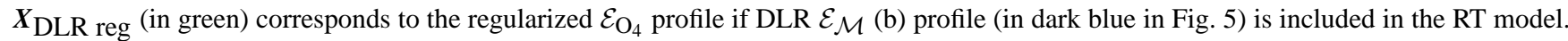
Right: Relative error of the (IUP-HD) $\mathcal{E}_{\mathrm{O}_{4}}$ retrieval.

the retrieval of the $\mathcal{E}_{\mathrm{O}_{4}}$ vertical profile shows a good agreement with the true state, with a maximum relative error of $20 \%$. This error is mostly dominated by the error in the forward RT model (i.e., coupling of ground albedo and aerosol load uncertainties), which can be understood as a miscalculation of the light path in a given layer. On the other hand, in regions where trace gas concentrations are close to the detection limit of the instrument (e.g., $\mathrm{O}_{4}$ in the UT/LS), the retrieval noise (the measurement error) dominates the total error of the retrieval.

\section{Results and discussions}

Since in the previous sections the robustness and consistency of the retrieval algorithm is validated in inter-comparison with the $\mathrm{O}_{4}$ vertical profile, confidence is gained in the novel method to retrieve vertical profile distribution of trace gases in the troposphere. Therefore we proceed to retrieve the targeted vertical tropospheric profile of $\mathrm{BrO}$ in the Arctic spring (Fig. 8). Overall, the inferred $\mathrm{BrO}$ profile appears to be Cshaped, having three distinct regions: the $\mathrm{BL}$ with high $\mathrm{BrO}$ mixing ratios (around $15 \mathrm{pptv}$ ), the free troposphere with $\mathrm{BrO}$ mixing ratios close to the detection limit $(\sim 1.5 \mathrm{pptv}$, averaged in altitude), and the UT/LS where the $\mathrm{BrO}$ mixing ra- tios increase with altitude. As indicated by the averaging kernels (Fig. 8, left panel), the inferred BrO tropospheric profile has roughly 10 degrees of freedom with an altitude resolution of about $1 \mathrm{~km}$.

Before the discussion can address further details of the inferred $\mathrm{BrO}$ profile and inter-comparisons with other studies can be made, specific aspects of our technique and potential implications for the inferred $\mathrm{BrO}$ need to be discussed.

Since there is a very small contribution of the true state to the null-space (averaging kernels very close to unity throughout the whole profile, Fig. 8, left), the regularized $\mathrm{BrO}$ profile presented in black in Fig. 8 (right) is a reasonably good but smoothed approximation of the $\mathrm{BrO}$ true state. In the first $1.5 \mathrm{~km}$ of the $\mathrm{BrO}$ profile (see Fig. 8, right), the forward model RT error is estimated as $80 \%$ of the total (black) error, and for the altitudes above, the measurement error dominates (70\%) the total $\mathrm{BrO}$ retrieval error. Also, the limited height resolution of this aircraft-borne limb technique for trace gas detection - as indicated by the full width at half maximum of the averaging kernels - suggests that details of the $\mathrm{BrO}$ profile shape within the first half kilometer of the BL are somewhat uncertain. This statement is particularly supported by the scattering due to particles that tend to radiatively smooth the profile shape in that region (Fig. 5). 

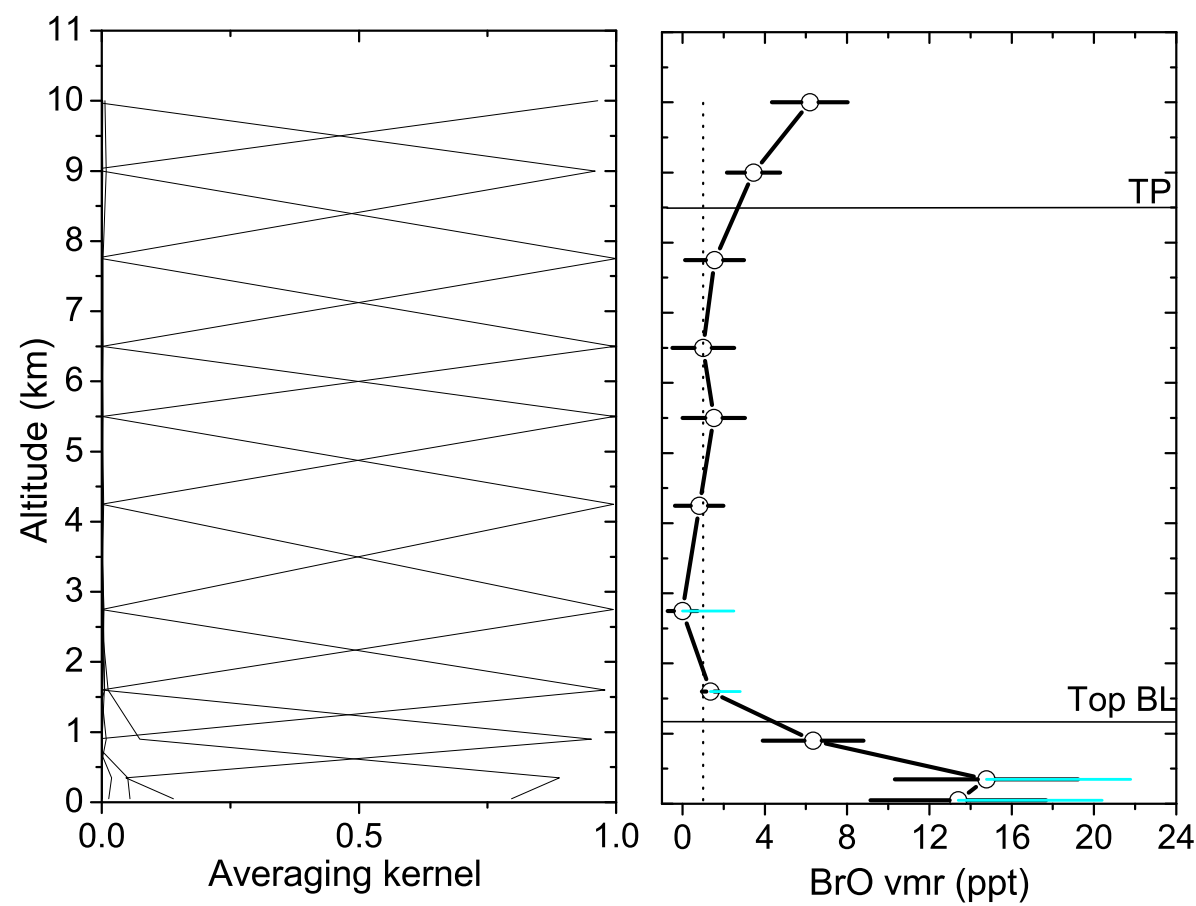

Fig. 8. Retrieval of the $\mathrm{BrO}$ vertical profile. Left: averaging kernel profile indicating 10 degrees of freedom. Right: BrO mixing ratio vertical profile. The black error bars include the retrieval noise and the uncertainty in forward RT model parameters such as the aerosol load and the ground albedo. The cyan error bars include biases in the error estimation if BrO horizontal gradients within each modeled atmospheric layer were present during the time of the measurements. The dashed vertical line indicates the BrO detection limit.

Furthermore, since the aircraft ascent from near the ground into the UT/LS took roughly $30 \mathrm{~min}$ and covered a latitudelongitude distance corresponding to $250 \mathrm{~km}$, the profile retrieval inherently condenses information gained from a 3-D plus time measurement into a 1-D effective profile. Consequently, sensitivity studies are performed aiming to estimate the horizontal sensitivity of the limb measurements during the aircraft ascent. For these studies a stratified atmosphere is considered and, thus, the retrieved aerosols (IUP-HD $\mathcal{E}_{\mathcal{M}}$ ) are supposed to have a homogeneous horizontal distribution. This assumption is believed to be valid for the passage over the high Arctic sea ice studied where, in the viewing direction of the mini-DOAS instrument, no open water (possible convection) was encountered. Main results from these sensitivity studies are: (1) the mini-DOAS instrument collected scattered skylight from a volume of air that (horizontally) extended 10 to $40 \mathrm{~km}$ from left side of the aircraft, (2) the Rayleigh scattering by air molecules dominates over particle scattering when the aircraft ascended from the BL up to the UT/LS, (3) most of the information gathered comes from the line of sight of the instrument. Particular details of these studies can be found in the work of Prados-Roman (2010) and some implications of those three findings are given below.

Finding (1) indicates a horizontal sensitivity of the limb measurements of 10 to $40 \mathrm{~km}$ (increasing with altitude).
Thus, any small scale variability of the targeted trace gas existing within that distance from the aircraft (depending on the altitude), is in fact averaged in our observations. This averaging may not limit the $\mathrm{BrO}$ profile retrieval in the free and upper troposphere where a horizontal homogeneity is probably justified. Conversely, strong $\mathrm{BrO}$ horizontal gradients may exist in the BL. In order to study possible $\mathrm{BrO}$ horizontal gradients within the horizontal instrument sensitivity range, forward RT analyses are performed. These analyses suggest that, within the first $600 \mathrm{~m}$, the $\mathrm{BrO}$ mixing ratio allowing to (independently) reproduce the measured $\mathrm{BrO}$ dSCD may be as large as 20 pptv (in cyan in Fig. 8). More insight into the horizontal variability of boundary layer $\mathrm{BrO}$ mixing ratios may be gained by analyzing the observations during the low level flight passage from 14:10 to 14:35 UT (refer to Fig. 1). This will be investigated in a forthcoming study. Following with the forward RT analyses to study possible $\mathrm{BrO}$ horizontal gradients above the $\mathrm{BL}$, between $1.2-3 \mathrm{~km}$, the $\mathrm{BrO}$ dSCDs measured may also be consistent with $\mathrm{BrO}$ mixing ratio of up to $2.5 \mathrm{pptv}$. Nevertheless, above $3 \mathrm{~km}$, the measurements were not reproducible within the error margins if a steady $\mathrm{BrO}$ mixing ratio larger than 3 pptv would be considered in the free troposphere. Moreover, GOME-2/MetOpA satellite observations indicate that, at the beginning of the aircraft ascent, an area of high $\mathrm{BrO}$ vertical column density (VCD) was crossed (see also Table 1). Thus, the retrieved BL 

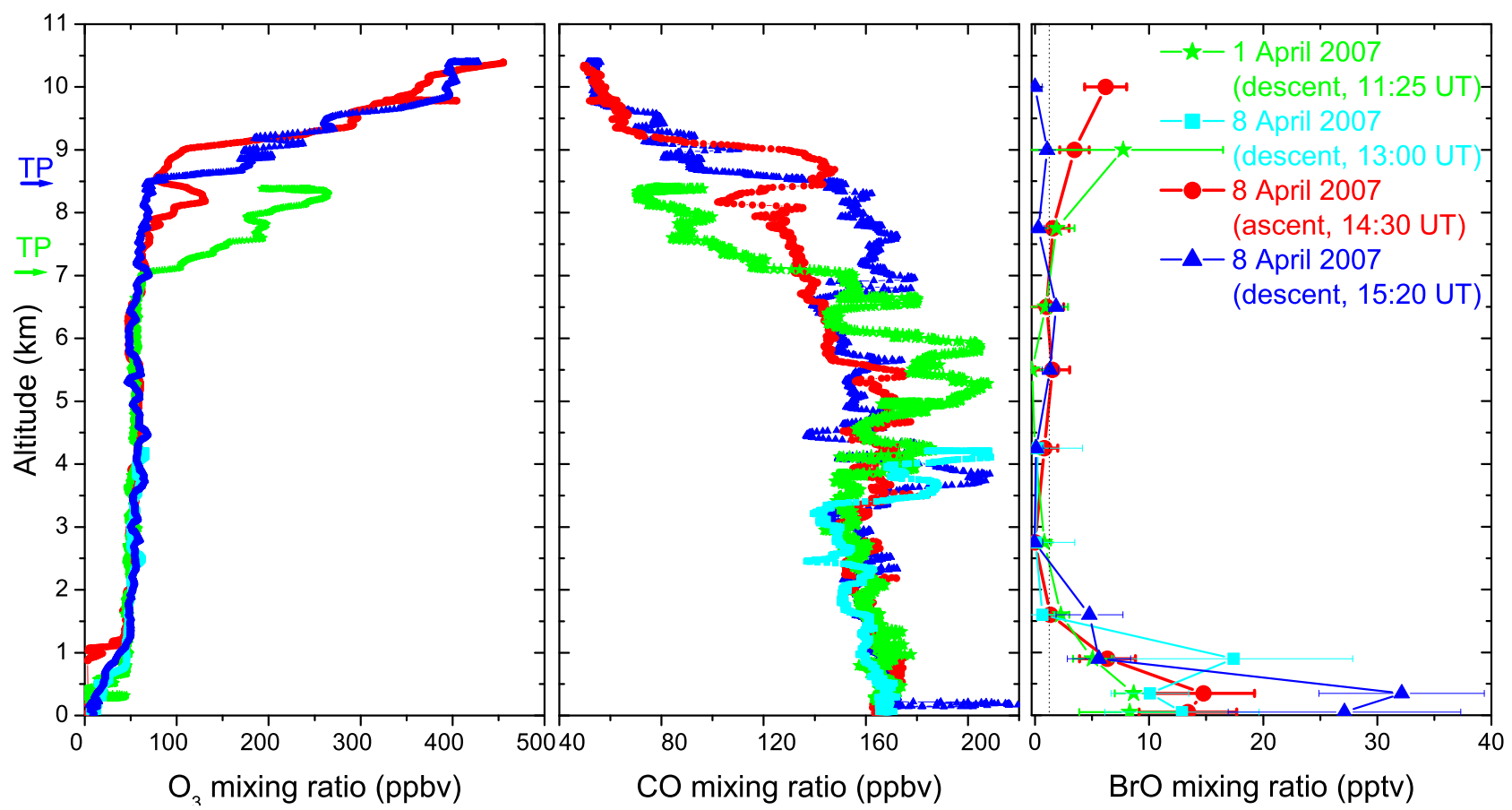

Fig. 9. Aircraft-borne measurements performed by the DLR $\left(\mathrm{O}_{3}\right.$ and $\left.\mathrm{CO}\right)$ and the IUP-HD group (BrO) on 1 April (green) and 8 (cyan, red, blue) during the ASTAR 2007 campaign. Note that the maximum altitude in the cyan profiles (descent at 13:00 UT, 8 April) is around 4 km. The tropopause height for 1 April (green) and 8 (blue) are indicated with arrows in the left panel. Further details of both sorties are given in Prados-Roman (2010). The dashed vertical line on the right panel indicates the BrO detection limit.

part of the profile shown in Fig. 8 may only be representative for the first part of the ascent.

As expected for measurements performed in the UV spectral range and in a rather clean atmosphere, finding (2) confirms that only in the boundary layer the Mie scattering may be relevant. Moreover, the radiative processes directed by Rayleigh scattering in the UT/LS suggests that the BrO profile retrieved at that altitude is independent from the assumption of any horizontal stratification of the aerosols' optical parameters at lower altitudes.

Another critical aspect of the retrieved $\mathrm{BrO}$ profiles in the UT/LS (and also of the retrieved IUP-HD $\mathcal{E}_{\mathcal{M}}$ profile from Fig. 5) addresses a possible contamination of the measured $\mathrm{BrO}$ absorption by photons being back-reflected from or near the ground, thus carrying to the location of detection some $\mathrm{BrO}$ absorption from the enhanced $\mathrm{BrO}$ concentration in the BL. However, finding (3) suggests e.g. that the $\mathrm{BrO}$ profile retrieved in the upper troposphere is not an artifact from $\mathrm{BrO}$ enhanced in the BL. This is also confirmed by forward modeling studies which show that the BrO dSCDs measured in the UT/LS can be explained (within the error bars) if no enhanced $\mathrm{BrO}$ is considered in the BL. Moreover, the retrieved $\mathrm{BrO}$ mixing ratios in the lowermost stratosphere compare well with expectations based on atmospheric $\mathrm{BrO}$ profile measurements performed during a large suite of balloon deployments into the lower and middle atmosphere from low, mid and high-latitudes during the past $15 \mathrm{yr}$ (e.g., Weidner et al., 2005; Dorf et al., 2006). Also, since the BrO averaging kernels are very close to unity throughout the whole vertical profile (see Fig. 8), the mentioned BrO surface contamination may in general be ruled out (although the width of the averaging kernel is also to be considered).

Next the inferred $\mathrm{BrO}$ profiles are put in the context of other in situ measured trace gases $\left(\mathrm{O}_{3}\right.$ and $\mathrm{CO}$ in Fig. 9). Such an investigation may also assist to test even further the consistency of the retrieved $\mathrm{BrO}$ profile. Figure 9 indicates (in red) that the slightly enhanced $\mathrm{BrO}$ found in the upper troposphere could be due to the transport of air masses from the lowermost stratosphere. Hence, this would simultaneously enhance $\mathrm{O}_{3}$ and $\mathrm{BrO}$ and deplete $\mathrm{CO}$. In fact, such transport events (tropopause folds which develop around cut-off lows), are known to occur frequently during the Arctic spring season (e.g, Shapiro et al., 1987; Stohl et al., 2003). These arguments enforce us to confirm that the $\mathrm{BrO}$ mixing ratios inferred in the UT/LS region represent a fairly accurate description of real physical quantities, and are not merely artifacts of the retrieval technique.

More difficult to discuss are the $\mathrm{BrO}$ mixing ratios inferred in the free troposphere. Indeed, there are reports of some pptv of $\mathrm{BrO}$ detected in the free troposphere during similar conditions (e.g., Fitzenberger et al., 2000). In addition, the averaging kernels of our $\mathrm{BrO}$ retrieval (Fig. 8, left) indicate 
Table 1. BrO VCD comparison between airborne and satellite measurements during the Arctic spring (2007). Note that VCD strat $_{\text {retrieved }}$ by the MPIC team may contain free tropospheric $\mathrm{BrO}$ (indicated as *). On the other hand, BrO columns inferred from balloon measurements performed in Kiruna $\left(67.9^{\circ} \mathrm{N}, 21.1^{\circ} \mathrm{E}\right)$ on 23 March 2003 and on 24 March 2004 are given as airborne VCD strat for 1 April 2007 and for 8 April 2007, respectively. Further details are given in Sect. 4. For information concerning the aircraft deployments of 1 and 8 April 2007 , the reader is referred to Prados-Roman (2010).

\begin{tabular}{|c|c|c|c|c|c|c|c|c|c|}
\hline \multirow{3}{*}{\multicolumn{2}{|c|}{$\begin{array}{l}\text { Date } \\
\text { Platform } \\
\text { Institute }\end{array}$}} & \multicolumn{3}{|c|}{1 April 2007} & \multicolumn{5}{|c|}{8 April 2007} \\
\hline & & \multirow{2}{*}{$\begin{array}{l}\text { Airborne } \\
\text { IUP-HD }\end{array}$} & \multicolumn{2}{|c|}{ Satellite } & \multirow{2}{*}{\multicolumn{3}{|c|}{$\begin{array}{c}\text { Airborne } \\
\text { IUP-HD }\end{array}$}} & \multicolumn{2}{|c|}{ Satellite } \\
\hline & & & MPIC & BIRA & & & & MPIC & BIRA \\
\hline \multicolumn{2}{|c|}{ UT (SZA) } & \multicolumn{3}{|c|}{$11: 25\left(79^{\circ}\right)$} & $13: 00\left(75^{\circ}\right)$ & $14: 30\left(78^{\circ}\right)$ & $15: 20\left(80^{\circ}\right)$ & \multicolumn{2}{|c|}{$14: 30\left(78^{\circ}\right)$} \\
\hline \multicolumn{2}{|c|}{ Latitude/Longitude } & \multicolumn{3}{|c|}{$81^{\circ} \mathrm{N} / 30^{\circ} \mathrm{E}$} & $79^{\circ} \mathrm{N} / 11.5^{\circ} \mathrm{E}$ & $80^{\circ} \mathrm{N} / 10^{\circ} \mathrm{E}$ & $78^{\circ} \mathrm{N} / 23^{\circ} \mathrm{E}$ & \multicolumn{2}{|c|}{$80^{\circ} \mathrm{N} / 10^{\circ} \mathrm{E}$} \\
\hline \multicolumn{2}{|l|}{ Units } & $\left(10^{13}\right.$ molec $\left.^{-2}\right)$ & \multicolumn{2}{|c|}{$\left(10^{13}\right.$ moleccm $\left.^{-2}\right)$} & \multicolumn{3}{|c|}{$\left(10^{13}\right.$ moleccm $\left.^{-2}\right)$} & \multicolumn{2}{|c|}{$\left(10^{13}\right.$ moleccm $\left.^{-2}\right)$} \\
\hline \multirow{3}{*}{$\mathrm{VCD}_{\text {trop }}$} & $\mathrm{BL}$ & $2.0 \pm 0.6$ & $2.5 \pm 1.0$ & - & $3.9 \pm 2.0$ & $3.8 \pm 1.2$ & $5.8 \pm 1.8$ & $2.8 \pm 1.0$ & - \\
\hline & Free & $1.0 \pm 1.0$ & - & - & $\geq(0.7 \pm 2.5)$ & $1.6 \pm 1.3$ & $1.5 \pm 1.1$ & - & - \\
\hline & TOTAL & $3.0 \pm 1.2$ & - & $4.0 \pm 1.5$ & $\geq(4.6 \pm 3.2)$ & $5.4 \pm 1.8$ & $7.3 \pm 2.1$ & - & $5.3 \pm 1.5$ \\
\hline \multirow{2}{*}{\multicolumn{2}{|c|}{$\begin{array}{l}\mathrm{VCD}_{\text {strat }} \\
\mathrm{VCD}_{\mathrm{TOTAI}}\end{array}$}} & $3.9 \pm 0.3$ & $4.2 \pm 0.6^{*}$ & $3.9 \pm 0.8$ & & $3.7 \pm 0.3$ & & $4.2 \pm 0.7^{*}$ & $3.7 \pm 0.8$ \\
\hline & & $6.9 \pm 1.2$ & $6.7 \pm 1.9$ & $7.9 \pm 2.3$ & $\geq(8.3 \pm 3.2)$ & $9.1 \pm 1.8$ & $11.0 \pm 2.1$ & $7.0 \pm 2.0$ & $9.0 \pm 2.3$ \\
\hline
\end{tabular}

the independence of the information inferred. Nevertheless, the small $\mathrm{BrO}$ mixing ratios close to or at the detection limit $(\leq 1.5 \mathrm{pptv})$ found for the free troposphere renders it difficult to quantify whether some $\mathrm{BrO}$ is actually present. One recent study reports on reactive bromine measurements $(\mathrm{HOBr}$, $\mathrm{Br}_{2}$ and $\mathrm{BrO}$ ) present in the $\mathrm{BL}$ and free troposphere during the Arctic spring of 2008 (Neuman et al., 2010). In Neuman et al. (2010) the amount of reactive bromine was found to be low ( $\leq 1 \mathrm{pptv}$ and typically close to detection limit) in the free troposphere. Photochemical arguments put forward by the authors (also valid for our conditions) suggest that most (if not all) of the detected reactive bromine was actually $\mathrm{HOBr}$ (reservoir) rather than $\mathrm{BrO}$. Since these arguments may also apply for our observations, we cannot conclude that $\mathrm{BrO}$ was unequivocally detected in the free troposphere during the ASTAR 2007 campaign.

Next the BrO detected within the BL of the Arctic troposphere during spring 2007 is considered (Fig. 9, right). Herein the near surface $\mathrm{BrO}$ mixing ratios show strong heterogeneities (with values between 8-30 pptv) with a general trend of decreasing $\mathrm{BrO}$ with height. This finding is well in agreement with previous observations of near surface $\mathrm{BrO}$ mixing ratios typically high ( $\geq 10 \mathrm{pptv}$ ) during the polar spring ODEs (e.g., Hausmann and Platt, 1994; Saiz-Lopez et al., 2007). However, even though in Neuman et al. (2010) $\mathrm{BrO}$ is found within our mixing ratio range, their measurements together with photochemical arguments indicate that most of the reactive bromine was actually $\mathrm{HOBr}$ (and possibly $\mathrm{Br}_{2}$ ), rather than $\mathrm{BrO}$. Since herein $\mathrm{BrO}$ is selectively detected by DOAS, their finding of $\mathrm{BrO}$ playing a minor role in the total reactive bromine during ODEs somehow contrasts with the overall finding of the present work, at least in situations where enough ozone is still available to oxidize the $\mathrm{Br}$ atoms formed either from $\mathrm{Br}_{2}$ or $\mathrm{BrCl}$ photolysis.
Another aspect of the bromine detection may address the variability of $\mathrm{BrO}$ in the $\mathrm{BL}$ due to the proximity to the open sea, broken sea ice (leads) or closed sea ice. In order to investigate potential source regions of reactive bromine, particular aircraft trajectories were planned with the goal of flying over these potential sources. As an example, different ascents and descents on 8 April probed the atmosphere over closed or broken sea ice (green, cyan and red profiles in Fig. 9), and over open ocean and scattered sea ice (blue profile in Fig. 9). Worth mentioning is that sensitivity studies indicate that heterogeneities in the forward model parameters may affect in unique ways the forward model error (and therefore the total error) for the inferred $\mathrm{BrO}$ tropospheric profiles presented in Fig. 9 (right). For instance, the error of the $\mathrm{BrO}$ profile at 14:30 UT (in red) is found to be largely determined by the aerosol load. On the other hand, the ground albedo variability dominates the error of the $\mathrm{BrO}$ profile at 15:20 UT (in blue). A first inspection of the measured $\mathrm{O}_{3}, \mathrm{CO}$ and $\mathrm{BrO}$ profiles (Fig. 9) reveals that the largest $\mathrm{BrO}$ mixing ratios (up to $30 \mathrm{pptv}$ ) were found during the descent over open ocean and scattered sea ice on 8 April (in blue), while the lowest ozone - very close to the detection limit of $3 \mathrm{ppbv}$ $(\mathrm{nmol} / \mathrm{mol})$ - was detected during the ascent on 8 April over closed and partly broken sea ice (in red). Since transport and photochemical processes as well as heterogeneous reactions may interact in a complicated manner, for the time being the source region for reactive bromine cannot be concluded. These facts, together with the sparsity of the collected data and their poor spatial resolution, complicates a firm conclusion on the potential source regions of the reactive bromine. Also a more detailed discussion of observations with respect to the sources of reactive bromine, its atmospheric transport and photochemical transformation is not within the scope of the present study but will require a detailed modeling of 


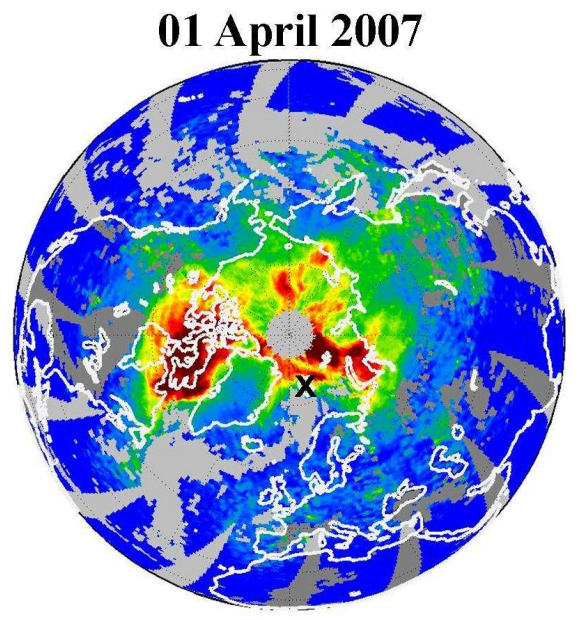

\section{Total}

\section{Stratospheric}
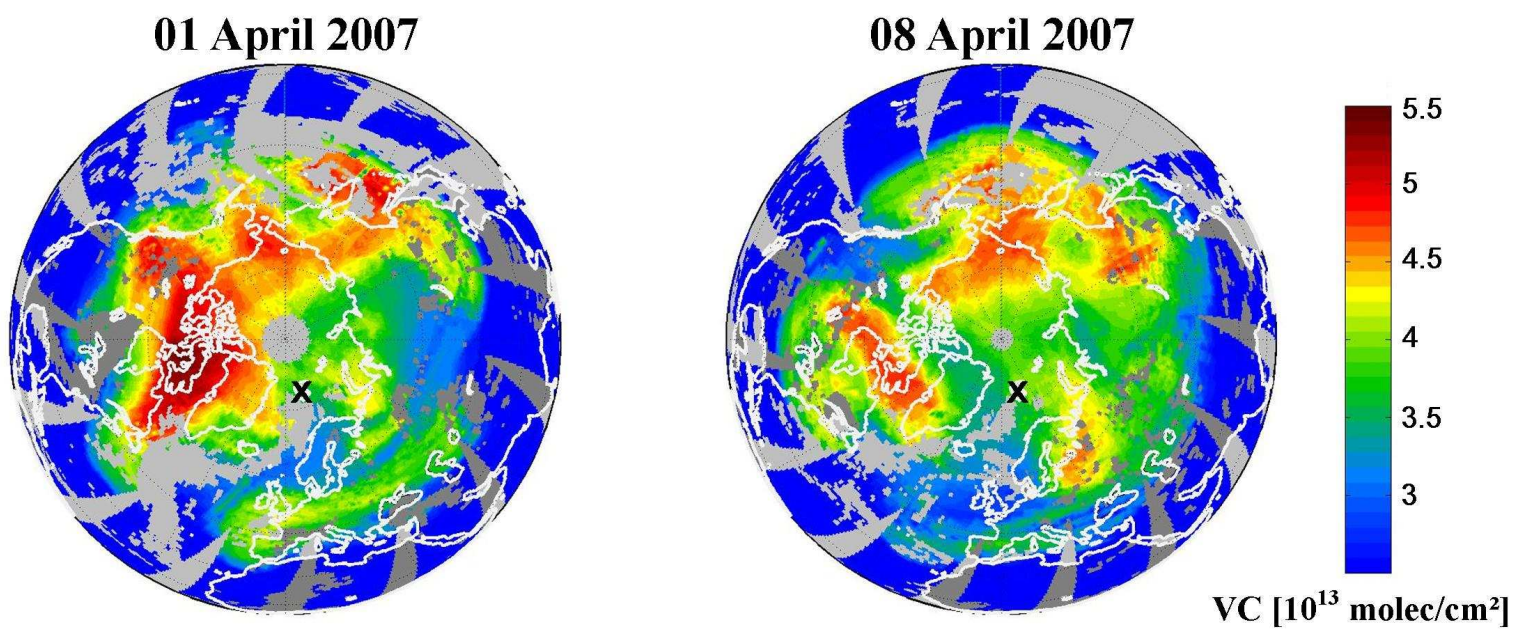

\section{Tropospheric}
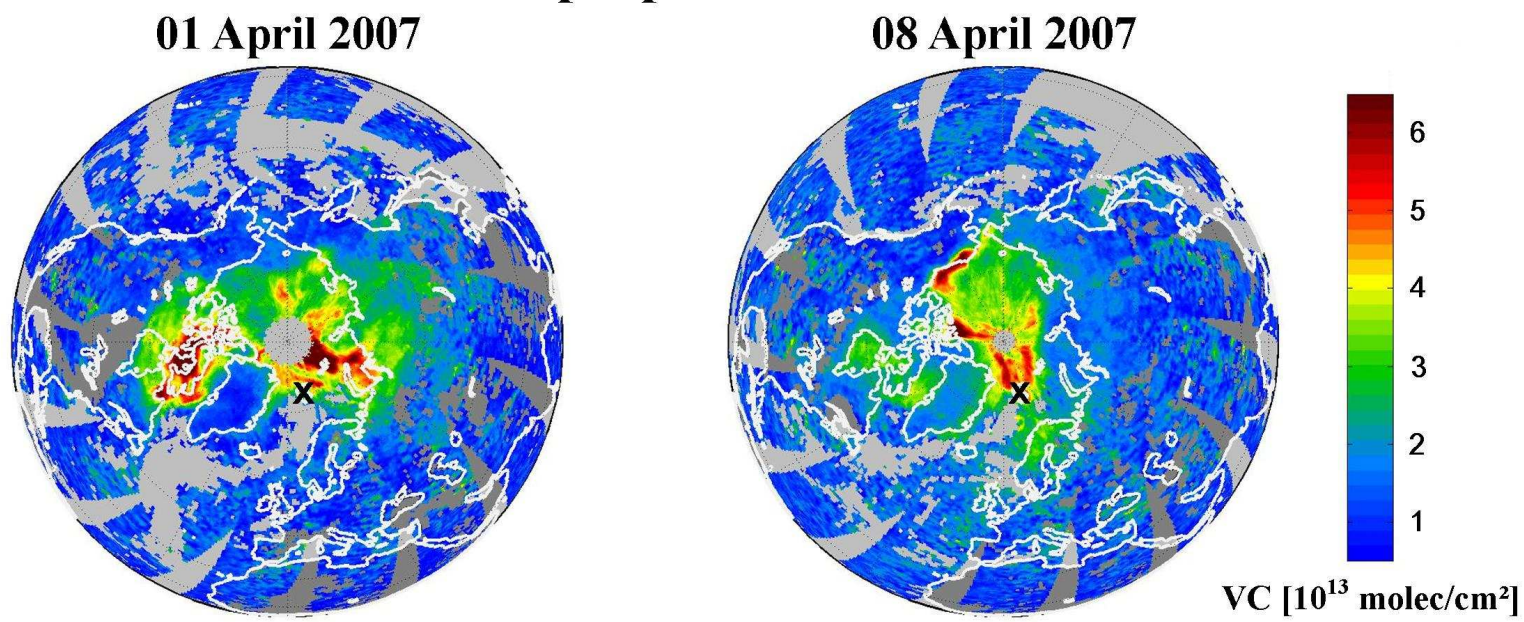

Fig. 10. GOME-2 total (upper panels), stratospheric (middle panels) and tropospheric (low panels) BrO Vertical Column Densities for the 1 and 8 April 2007 (left and right column, resp.). The island of Spitsbergen, base of the ASTAR 2007 campaign, is marked with black crosses. Details of the retrieval method are given in Theys et al. (2011). 
the relevant processes. Such an approach is the objective of a forthcoming study.

Finally, our data are inter-compared with simultaneous satellite-borne $\mathrm{BrO}$ observations. The satellite data, derived from GOME-2/MetOp-A measurements (e.g., Wagner and Platt, 1998; Theys et al., 2011), consist of total stratospheric and tropospheric $\mathrm{BrO}$ vertical column densities (VCD) retrieved using two different algorithms developed by the MaxPlanck-Institute for Chemistry (MPIC), and by the BIRAIASB/TEMIS groups (see Fig. 10). The satellite retrievals of both groups are based on a residual technique that combines measured total $\mathrm{BrO}$ slant columns and estimates of the $\mathrm{BrO}$ absorption in the stratosphere. Furthermore, stratospheric and tropospheric air mass factors are applied in order to account for changes in measurement sensitivity in both stratospheric and tropospheric layers. The BIRA-IASB team applies a stratospheric correction based on the $\mathrm{BrO}$ climatology described by Theys et al. (2009) which uses estimates of the tropopause height (derived from ECMWF data), as well as $\mathrm{O}_{3}$ and $\mathrm{NO}_{2}$ vertical columns simultaneously retrieved by GOME-2 (more details can be found in Theys et al., 2011). The MPIC team uses a slightly different method under current development. In this case the stratospheric contribution to the measured slant column is estimated using a filter algorithm based on statistical ensembles. The method relies on the following assumptions: (1) There is a linear correlation between stratospheric $\mathrm{O}_{3}$ and $\mathrm{BrO}$ slant column densities (Salawitch et al., 2010). (2) Similarly to the parameterization used by the BIRA-IASB team (Theys et al., 2009, 2011), the ratio of the slant columns of $\mathrm{BrO}$ and $\mathrm{O}_{3}$ depends on the $\mathrm{BrO} / \mathrm{Bry}$ chemistry altered by the stratospheric concentration of $\mathrm{NO}_{2}$, and on the solar zenith angle. (3) Apart from stratospheric photo-chemistry, deviations toward a higher $\mathrm{BrO} / \mathrm{O}_{3}$ indicate enhanced $\mathrm{BrO}$ below the tropopause. However, a retrieval based on these three basic assumptions is not able to clearly distinguish between any background $\mathrm{BrO}$ in the troposphere and the stratosphere (i.e., the VCDstrat may contain free tropospheric $\mathrm{BrO}$ ). Therefore, the MPIC approach merely allows us to identify and study observations that have an "above normal" $\mathrm{BrO}$ column density (indicated as * in Table 1). Note that two different satellite retrievals are considered for this inter-comparison exercise in order to investigate the consistency of the airborne and the satellite $\mathrm{BrO}$ VCD regardless the retrieval method applied to the satellite measurements.

In order to compare the satellite columns with the airborne results, only satellite pixels with overpasses $30 \mathrm{~min}$ before and after the duration of the passages are considered. In addition to the satellite pixels intercepting the Falcon flight track, pixels falling roughly $20 \mathrm{~km}$ on the left side of the track (in the mini-DOAS viewing direction) are also taken into account. Adding those pixels parallel to the flight track aim at considering an averaged horizontal sensitivity of the limb measurements throughout the aircraft ascent. Finally, based on measured $\mathrm{O}_{4}$ airmass factors, only the satellite pixels dis- playing the highest sensitivity to surface $\mathrm{BrO}$ have been kept for the comparison.

Table 1 provides an overview of the inter-comparison exercise. Shown are the tropospheric $\mathrm{BrO}$ columns inferred from the flights on 1 and 8 April during the ASTAR 2007 campaign (see also Fig. 9, right) and integrated over the BL, the free troposphere and the entire troposphere. In addition, estimates of stratospheric $\mathrm{BrO}$ columns inferred from balloon measurements are provided. Those measurements were performed in Kiruna $\left(67.9^{\circ} \mathrm{N}, 21.1^{\circ} \mathrm{E}\right)$ on 23 March 2003 and on 24 March 2004. Details of those balloon flights, characterized by a tropopause altitude of $8 \mathrm{~km}$ and $8.9 \mathrm{~km}$ (resp.), are given in the work of Dorf et al. (2006). In the cases of the cloud-free passages flown over the sea ice of 1 April 2007 (11:25 UT) and 8 April 2007 (14:30 UT), our airborne data (IUP-HD) are compared to the satellite columns (MPIC and BIRA). Note that no satellite data are given for the 13:00 and 15:20 UT profiles on 8 April 2007, due to the small number of satellite pixels meeting our selection criterion.

As shown in Table 1, within the limits of the experimental errors, the integrated $\mathrm{BrO}$ column amounts using the airborne and the satellite approaches compare reasonably well. Differences between the three groups may be due to different wavelength range chosen for the $\mathrm{BrO}$ spectral retrieval (airborne retrieval: 346-359 nm, BIRA: 332-359 nm and MPIC: 336$360 \mathrm{~nm}$ ), although the possibility that different air masses were sampled cannot be ruled out. On the other hand, deviations between the two satellite retrievals may be attributed to a different choice of the VCD retrieval algorithm (MPIC applies a normalization following the method published by Richter et al. (2002) while the BIRA product does not apply any normalization procedure). Since the ground albedo significantly alters the sensitivity for the satellite detection of trace gases close to the surface, the ground albedo may also play a role in those differences. In these studies, the MPIC group uses the same surface albedo as the mean value used by the IUP-HD group (79\%). On the other hand the BIRA group uses variable surface albedo values per pixels, with mean values of $75 \%$ (1 April) and $68 \%$ (8 April) based on Koelemeijer et al. (2003) climatology. Overall, worth mentioning is also that in the selected passages and compared to airborne values, the satellite retrievals do not systematically underestimate $\mathrm{BrO}$.

\section{Conclusions}

The present study reports on recent developments of aircraftborne DOAS (Differential Optical Absorption Spectroscopy) limb measurements, the tropospheric profile retrieval of important atmospheric trace gases (e.g., BrO), and its validation. The data discussed within the study were obtained during deployments of a novel light-weight mini-DOAS instrument on the DLR-Falcon aircraft that conducted research flights around Svalbard during the polar spring ASTAR 2007 field campaign. Major challenges in the interpretation of the 
collected optical data and the validation of the inferred trace gas profiles arose with the predominant influence of the presence of spatially and temporal variable amounts of aerosols within the probed atmosphere, as well as the high but spatially variable ground albedo.

In order to overcome these complications, a two step approach was chosen. First, an effective vertical profile of the aerosol extinction coefficient was inferred from measured Sun normalized radiances. This inverted aerosol profile served then as an input parameter in the forward RT model which is needed for the regularization of tropospheric trace gas vertical profiles retrieved from measured dSCDs. Comparison of the retrieved aerosol extinction profile and that derived from in situ size distribution measurements indicates a limitation of the aerosol retrieval constrained to one single type of aerosol. However, the consistency of the effective aerosol extinction and tropospheric trace gas retrieval comes from forward modeling studies and, in addition, is validated by inter-comparing a regularized $\mathcal{E}_{\mathrm{O}_{4}}$ profile with the true $\mathcal{E}_{\mathrm{O}_{4}}$.

Once the appropriate parameters for the forward RT model were set, profiles of tropospheric $\mathrm{BrO}$ with typically $10 \mathrm{de}-$ grees of freedom and an averaged detection limit of $1.5 \mathrm{pptv}$ could be inferred. Sensitivity studies indicated a resolution of the retrieved profiles of $1 \mathrm{~km}$ in the vertical. Since vertical profiles of $\mathrm{BrO}$ are not known by other means, airborne total column amounts of tropospheric and stratospheric $\mathrm{BrO}$ were inter-compared with simultaneous measurements of collocated GOME-2/MetOp-A satellite measurements. This inter-comparison generally shows reasonably good agreement within the given errors of both methods, thus providing confidence that for the studied cases neither the airborne profile measurements nor the satellite measurements are systematically biased.

The inferred BrO profiles generally show large and heterogeneous mixing ratios within the BL (8-30 pptv), and small mixing ratios within the free troposphere $(\leq 1.5 \mathrm{pptv})$. In the upper troposphere and lowermost stratosphere, the inferred variable mixing ratios (1-4 pptv) increase with height. The latter two findings can be explained by the known atmospheric photochemistry of bromine, and by the transport of stratospheric air masses to tropospheric altitudes (as seen by simultaneous $\mathrm{O}_{3}$ and $\mathrm{CO}$ measurements, e.g., Pan et al., 2004). The former finding points to halogen activation within air masses of so-called ozone depletion events (e.g., Simpson et al., 2007). The inferred BrO vertical profiles presented are the first of their kind and they complement recent reports of profile measurements of reactive bromine (mostly $\mathrm{HOBr}$ ) performed in a similar situation.
Future applications of aircraft-borne limb technique are wide-spread, such as measurements of atmospheric halogen radical profiles $(\mathrm{BrO}, \mathrm{IO}, \mathrm{OClO}, \mathrm{OIO}, \ldots)$ above oceanic waters of large biological activity (e.g., along the shores of large tides, the tropical Atlantic, the tropical Eastern and Western Pacific), in polar regions, within plumes of volcanic emissions, over salt lakes, or even in the free troposphere and lowermost stratosphere. Other applications of the technique may focus on studies where other gases, also accessible with UV/vis/near-IR DOAS technique $\left(\mathrm{O}_{3}, \mathrm{NO}_{2}, \mathrm{HONO}, \mathrm{CH}_{2} \mathrm{O}\right.$, $\mathrm{C}_{2} \mathrm{H}_{2} \mathrm{O}_{2}$, all three phases of water, etc.), are important. Such investigations are planned within future deployments of the novel research aircraft DLR-HALO. In addition, the retrieval of aerosol and cloud particle optical properties simultaneously measured can improve the accuracy of the key trace gas retrievals (e.g. Wagner et al., 2004; Friess et al., 2006; Wagner et al., 2009b; Vlemmix et al., 2010). Furthermore, the retrieval of optical properties of particles- such as an extinction profile - represents a research field with great potential for, e.g., radiative forcing and climate feedback investigations (e.g. Daniel, 2006; Schofield et al., 2007).

\section{Supplementary material related to this article is available online at: http://www.atmos-meas-tech.net/4/1241/2011/ amt-4-1241-2011-supplement.zip.}

Acknowledgements. Funding for this study came from the Pf 384/5-1 grant provided by the Deutsche Forschungsgemeinschaft (DFG). The ASTAR 2007 campaign and the Falcon flights were funded by the Alfred Wegener Institute for Polar and Marine Research (AWI), and the Deutsches Zentrum für Luft und Raumfahrt (DLR). We thank B. Simmes (formerly in IUP-HD), for his work during the ASTAR 2007 campaign. We also thank the personal from the DLR (in particular the flight department) for the assistance before and during the ASTAR 2007 campaign, and for providing the videos obtained by the camera mounted in the Falcon. Furthermore, we appreciate the comments of A. Ehrlich (Leipzig Institute for Meteorology) on the Arctic ground albedo in the UV spectral range. C. Prados-Roman and H. Sihler thank the International Max Plank Research School for Atmospheric Chemistry and Physics (IMPRS, Mainz) for the research network and funding offered. C. Prados-Roman thanks also M. Martinez and R. von Glasow for their enriching discussions regarding halogen compounds in the polar atmosphere.

Edited by: F. Boersma

\section{References}

Aliwell, S. R., Van Roozendael, M., Johnston, P. V., Richter, A., Wagner, T., Arlander, D. W., Burrows, J. P., Fish, D. J., Jones, R. L., Tornkvist, K. K., Lambert, J.-C., Pfeilsticker, K., and Pundt, I.: Analysis for $\mathrm{BrO}$ in zenith-sky spectra: an intercomparison exercise for analysis improvement, J. Geophys. Res., 107(D14), 4199, doi:10.1029/2001JD000329, 2002. 
Burrows, J. P., Richter, A., Dehn, A., Deters, B., Himmelmann, S., Voigt, S., and Orphal, J.: Atmospheric remote-sensing reference data from GOME - 2. Temperature-dependent absorption cross sections of $\mathrm{O}_{3}$ in the 231-794 nm range, J. Quant. Spectrosc. Ra., 61, 4, 509-517, 1999.

Ceccherini, S.: Analytical determination of the regularization parameter in the retrieval if atmospheric vertical profiles, Opt. Lett., 30(19), 2554-2556, 2005.

Daniel, J. S., Portmann, R. W., Miller, H. L., Solomon, S., Langford, A. O., Eubank, C. S., Schofield, R., Turner, D. D., and Shupe, M.D.: Cloud property estimates from zenith spectral measurements of scattered sunlight between 0.9 and $1.7 \mu \mathrm{m}, \mathrm{J}$. Geophys. Res., 111, D16208, doi:10.1029/2005JD006641, 2006.

Deutschmann, T.: Atmospheric Radiative Transfer Modelling with Monte Carlo Methods, Institute of environmental physics University of Heidelberg, 82 pp., 2008.

Deutschmann, T., Beirle, S., Friess, U., Grzegorski, M., Kern, C., Kritten, L., Platt, U., Prados-Roman, C., Pukite, J., Wagner, T., Werner, B., and Pfeilsticker, K.: The Monte Carlo atmospheric radiative transfer model McArtim: introduction and validation of Jacobians and 3-D features, J. Quant. Spectrosc. Ra., 112(6), 1119-1137, ISSN 0022-4073, doi:10.1016/j.jqsrt.2010.12.009, 2011.

Dorf, M., Bösch, H., Butz, A., Camy-Peyret, C., Chipperfield, M. P., Engel, A., Goutail, F., Grunow, K., Hendrick, F., Hrechanyy, S., Naujokat, B., Pommereau, J.-P., Van Roozendael, M., Sioris, C., Stroh, F., Weidner, F., and Pfeilsticker, K.: Balloonborne stratospheric $\mathrm{BrO}$ measurements: comparison with Envisat/SCIAMACHY BrO limb profiles, Atmos. Chem. Phys., 6, 2483-2501, doi:10.5194/acp-6-2483-2006, 2006.

Ehrlich, A.: The impact of ice crystals on radiative forcing and remote sensing of arctic boundary-layer mixedphase clouds, Ph.D. thesis, Johannes Gutenberg University Mainz, Germany, http://www.oma.be/BIRA-IASB/Molecules/ BrO/WinDOAS-SUM-210b.pdf, 2009.

Ehrlich, A., Bierwirth, E., Wendisch, M., Gayet, J.-F., Mioche, G., Lampert, A., and Heintzenberg, J.: Cloud phase identification of Arctic boundary-layer clouds from airborne spectral reflection measurements: test of three approaches, Atmos. Chem. Phys., 8, 7493-7505, doi:10.5194/acp-8-7493-2008, 2008.

Emde, C., Buras, R., Mayer, B., and Blumthaler, M.: The impact of aerosols on polarized sky radiance: model development, validation, and applications, Atmos. Chem. Phys., 10, 383-396, doi:10.5194/acp-10-383-2010, 2010.

Fayt, C. and van Roozendael, M.: WinDOAS 2.1. Software User Manual, technical report, available at: http://www.oma. be/BIRA-IASB/Molecules/BrO/WinDOAS-SUM-210b.pdf, last access: July 2010, 2001.

Fitzenberger, R., Bösch, H., Camy-Peyret, C., Chipperfield, M. P., Harder, H., Platt, U., Sinnhuber, B. M., Wagner, T., and Pfeilsticker, K.: First Profile Measurements of Tropospheric BrO, Geophys. Res. Lett., 27, 2921-2925, 2000.

Friess, U., Monks, P. S., Remedios, J. J., Rozanov, A., Sinreich, R., Wagner, T., and Platt, U.: MAX-DOAS O 4 measurements: a new technique to derive information on atmospheric aerosols: 2. Modeling studies, J. Geophys. Res.-Atmos., 111, D14203, doi:10.1029/2005JD006618, 2006.

Greenblatt, G. D., Orlando, J. J., Burkholder, J. B., and Ravishankara, A. R.: Absorption measurements of oxygen between
330 and 1140 nm, J. Geophys. Res., 95, 18577-18582, 1990.

Hansen, P. C.: Analysis of discrete ill-posed problems by means of the L-curve, SIAM Rev., 34, 561-580, 1992.

Hansen, P. C.: Regularization tools version 4.0 for Matlab 7.3, Numer. Algorithms, 46, 189-194, 2007.

Hasekamp, O. P. and Landgraf, J.: Ozone profile retrieval from backscattered ultraviolet radiances: The inverse problem solved by regularization, J. Geophys. Res., 106(D8), 8077-8088, 2001.

Hausmann, M. and Platt, U.: Spectroscopic measurement of bromine oxide and ozone in the high Arctic during Polar Sunrise Experiment 1992, JGR, 99, 25399-25414, 1994.

Henyey, L. C. and Greenstein, J. L.: Diffuse radiation in the Galaxy, Astrophys. J., 93, 70-83, 1941.

Hermans, C.: http://spectrolab.aeronomie.be/o2_o4info.htm, last access: August 2010, 2002.

Koelemeijer, R. B. A., de Haan, J. F., and Stammes, P.: A database of spectral surface reflectivity in the range $335-772 \mathrm{~nm}$ derived from $5.5 \mathrm{yr}$ of GOME observations, J. Geophys. Res. Atmos., 108(D2), 4070, doi:10.1029/2002JD002429, 2003.

Kritten, L., Butz, A., Dorf, M., Deutschmann, T., Kühl, S., PradosRoman, C., Puksīe, J., Rozanov, A., Schofield, R., and Pfeilsticker, K.: Time dependent profile retrieval of UV/vis absorbing radicals from balloon-borne limb measurements - a case study on NO2 and O3, Atmos. Meas. Tech., 3, 933-946, doi:10.5194/amt3-933-2010, 2010.

Lampert, A., Ehrlich, A., Dörnbrack, A., Jourdan, O., Gayet, J.F., Mioche, G., Shcherbakov, V., Ritter, C., and Wendisch, M.: Microphysical and radiative characterization of a subvisible midlevel Arctic ice cloud by airborne observations - a case study, Atmos. Chem. Phys., 9, 2647-2661, doi:10.5194/acp-9-26472009, 2009.

Langford, A. O., Schofield, R., Daniel, J. S., Portmann, R. W., Melamed, M. L., Miller, H. L., Dutton, E. G., and Solomon, S.: On the variability of the Ring effect in the near ultraviolet: understanding the role of aerosols and multiple scattering, Atmos. Chem. Phys., 7, 575-586, doi:10.5194/acp-7-575-2007, 2007.

Landgraf, J., Hasekamp, O. P., van Deelen, R., and Aben, I. : Rotional Raman scattering of polarized light in the Earth atmosphere: a vector radiative transfer model using the radiative transfer perturbation theory approach, J. Quant. Spectrosc. Ra., 87, 399-433, 2004.

Leitão, J., Richter, A., Vrekoussis, M., Kokhanovsky, A., Zhang, Q. J., Beekmann, M., and Burrows, J. P.: On the improvement of $\mathrm{NO}_{2}$ satellite retrievals - aerosol impact on the airmass factors, Atmos. Meas. Tech., 3, 475-493, doi:10.5194/amt-3-475-2010, 2010.

Levenberg, K.: A Method for the Solution of Certain Non-Linear problems in Least Squares, Q. Appl. Math., 2, 164-168, 1944.

Marquardt, D. W.: An algorithm for the least-squares estimation of nonlinear parameters, SIAM, J. Appl. Math., 11, 431-441, doi:10.1137/0111030, 1963 .

Neuman, J. A., Nowak, J. B., Huey, L. G., Burkholder, J. B., Dibb, J. E., Holloway, J. S., Liao, J., Peischl, J., Roberts, J. M., Ryerson, T. B., Scheuer, E., Stark, H., Stickel, R. E., Tanner, D. J., and Weinheimer, A.: Bromine measurements in ozone depleted air over the Arctic Ocean, Atmos. Chem. Phys., 10, 6503-6514, doi:10.5194/acp-10-6503-2010, 2010.

O’Dowd, C., Jimenez, J. L., Bahreini, R., Flagan, R. C., Seinfeld, J. H., Hämeri, K., Pirjola, L., Kulmala, M., Jennings, S. G., 
and Hoffmann, T.: Marine aerosol formation from biogenic iodine emissions, Nature, 417, 632-636, 2002.

Pan, L., Randel, W., Gary, B., Mahoney, M., and Hintsa, E: Definitions and sharpness of the extratropical tropopause: A trace gas perspective. J. Geophys. Res, 109, D23103, doi:10.1029/2004JD004982, 2004.

Pfeilsticker, K., Bösch, H., Camy-Peyret, C., and Fitzenberger, R.: First atmospheric profile measurements of UV/vis $\mathrm{O}_{4}$ absorption band intensities: implications for the spectroscopy, and the formation enthalpy of the $\mathrm{O}_{2}-\mathrm{O}_{2}$ dimer, Geophys. Res. Lett., 28(24), 4595-4598, 2001.

Phillips, P.: A technique for the numerical solution of certain integral equations of the first kind, J. Assoc. Comput. Mach., 9, 84-97, 1962.

Platt, U. and Stutz, J.: Differential Optical Absorption Spectroscopy (DOAS), Principle and Applications, ISBN 3-34021193-4, Springer, Berlin, 2008.

Prados-Roman, C.: Aircraft-borne spectroscopic limb measurements of trace gases absorbing in the UV-A spectral range. Investigations of bromine monoxide in the Arctic troposphere, Ph.D. thesis, Heidelberg University, http://archiv.ub.uni-heidelberg.de/ volltextserver/volltexte/2011/11451, 2010.

Press, W. H., Flannery, B. P., Teukolsky, S. A., and Vetterling, W. T.: Numerical recipes: The art of scientific computing, ISBN 0-52143108-5, Cambridge University Press, Cambridge, 1986.

Quinn, P. K., Shaw, G., Andrews, E., Dutton, E. G., RuohoAirola, T., and Gong, S. L.: Arctic haze: Current trends and knowledge gaps, Tellus B, 59, 99-114, 2007.

Richter, A., Wittrock, F., Eisinger, M., and Burrows, J. P.: GOME Observations of Tropospheric BrO in Northern Hemispheric Spring and Summer 1997, Geophys. Res. Lett., 25(14), 26832686, doi:10.1029/98GL52016, 1998.

Richter, A., Wittrock, F., Ladstätter-Weissenmayer, A., and Burrows, J. P.: GOME measurements of stratospheric and tropospheric BrO, Adv. Space Res., 29, 1667-1672, 2002.

Ridley, B. A., Atlas, E. L., Montzka, D. D., Browell, E., V., Cantrell, C., A., Blake, D., R., Blake, N., J., Cinquini, L., Coffey, M., T., Emmons, L., K., Cohen, R., C., DeYoung, R., J., Dibb, J., E., Eisele, F., L., Flocke, F., M., Fried, A., Grahek, F., E., Grant, W., B., Hair, J., W., Hannigan, J., W., Heikes, B., J., Lefer, B, L., Mauldin, R., L., Moody, J., L., Shetter, R., E., Snow, J., A., Talbot, R., W, Thornton, J., A., Walega, J., G., Weinheimer, A., J., Wert, B., P., and Wimmers, A. J.: Ozone depletion events observed in the high latitude surface layer during the TOPSE aircraft program, J. Geophys. Res., 108(D4), 8356, doi:10.1029/2001JD001507, 2003.

Rodgers, C. D.: Inverse methods for atmospheric sounding, World Scientific, Singapore New Jersey London Hong Kong, 2000.

Salawitch, R. J., Canty, T., Kurosu, T., Chance, K., Liang, Q., da Silva, A., Pawson, S., Nielsen, J. E., Rodriguez, J. M., Bhartia, P. K., Liu, X., Huey, L. G., Liao, J., Stickel, R. E., Tanner, D.J., Dibb, J .E., Simpson, W. R., Donohoue, D., Weinheimer, A., Flocke, F., Knapp, D., Montzka, D., Neuman, J. A., Nowak, J. B., Ryerson, T. B., Oltmans, S., Blake, D. R., Atlas, E. L., Kinnison, D. E., Tilmes, S., Pan, L.L., Hendrick, F., Van Roozendael, M., Kreher, K., Johnston, P. V., Gao, R. S., Johnson, B., Bui, T. P., Chen, G., Pierce, R. B., Crawford, J. H., and Jacob, D. J: A new interpretation of total column BrO during Arctic Spring, Geophys. Res. Lett., 37, L21805, doi:10.1029/2010GL043798,
2010.

Saiz-Lopez, A., Mahajan, A. S., Salmon, R. A., Bauguitte, S. J. B., Jones, A. E., Roscoe, H. K., and Plane, J. M. C.: Boundary layer halogens in coastal AntArctica, Science, 317, 348, doi:10.1126/science.1141408, 2007.

Schofield, R., Daniel, J. S., Portmann, R. W., Miller, H. L. R., Solomon, S., Eubank, C. S., Melamed, M. L., Langford, A. O., Shupe, M. D., and Turner, D. D.: Retrieval of effective radius and liquid water path from ground-based instruments: A case study at Barrow, Alaska, J. Geophys. Res., 112, D21203, doi:10.1029/2007JD008737, 2007.

Shapiro, M. A., Hampel, T., and Krueger, A. J.: The Arctic tropopause fold, Mon. Weather Rev. 115, 444-454, 1987.

Simpson, W. R., von Glasow, R., Riedel, K., Anderson, P., Ariya, P., Bottenheim, J., Burrows, J., Carpenter, L. J., Frieß, U., Goodsite, M. E., Heard, D., Hutterli, M., Jacobi, H.-W., Kaleschke, L., Neff, B., Plane, J., Platt, U., Richter, A., Roscoe, H., Sander, R., Shepson, P., Sodeau, J., Steffen, A., Wagner, T., and Wolff, E.: Halogens and their role in polar boundary-layer ozone depletion, Atmos. Chem. Phys., 7, 4375-4418, doi:10.5194/acp-74375-2007, 2007.

Steck, T.: Methods for determining regularization for atmospheric retrieval problems, Appl. Optics, 41(9), 1788-1797, 2002.

Steffen, A., Douglas, T., Amyot, M., Ariya, P., Aspmo, K., Berg, T., Bottenheim, J., Brooks, S., Cobbett, F., Dastoor, A., Dommergue, A., Ebinghaus, R., Ferrari, C., Gardfeldt, K., Goodsite, M. E., Lean, D., Poulain, A. J., Scherz, C., Skov, H., Sommar, J., and Temme, C.: A synthesis of atmospheric mercury depletion event chemistry in the atmosphere and snow, Atmos. Chem. Phys., 8, 1445-1482, doi:10.5194/acp-8-1445-2008, 2008.

Stohl, A., Bonasoni, P., Cristofanelli, P., Collins, W., Feichter, J., Frank, A., Forster, C., Gerasopoulos, E., Gäggeler, H., James, P., Kentarchos, T., Kreipl, S., Kromp-Kolb, H., Krüger, B., Land, C., Meloen, J., Papayannis, A., Priller, A., Seibert, P., Sprenger, M., Roelofs, G. J., Scheel, E., Schnabel, C., Siegmund, P., Tobler, L., Trickl, T., Wernli, H., Wirth, V., Zanis, P., and Zerefos, C.: Stratosphere-troposphere exchange: a review, and what we have learned from STACCATO, J. Geophys. Res., 108(D12), 8516, doi:10.1029/2002JD002490, 2003.

Stutz, J. and Platt, U.: Numerical analysis and estimation of the statistical error of differential optical absorption spectroscopy measurements with least-squares methods, Appl. Optics., 35, 60416053, 1996.

Theys, N., Van Roozendael, M., Errera, Q., Hendrick, F., Daerden, F., Chabrillat, S., Dorf, M., Pfeilsticker, K., Rozanov, A., Lotz, W., Burrows, J. P., Lambert, J.-C., Goutail, F., Roscoe, H. K., and De Mazière, M.: A global stratospheric bromine monoxide climatology based on the BASCOE chemical transport model, Atmos. Chem. Phys., 9, 831-848, doi:10.5194/acp-9-831-2009, 2009.

Theys, N., Van Roozendael, M., Hendrick, F., Yang, X., De Smedt, I., Richter, A., Begoin, M., Errera, Q., Johnston, P. V., Kreher, K., and De Mazière, M.: Global observations of tropospheric BrO columns using GOME-2 satellite data, Atmos. Chem. Phys., 11, 1791-1811, doi:10.5194/acp-11-1791-2011, 2011.

Tikhonov, A. N.: On the solution of incorrectly stated problems and method of regularization, Dokl. Akad. Nauk. SSSR, 151, 501504, 1963. 
Tikhonov, A. N. and Arsenin, V. Y.: Solutions of Ill-Posed Problems, ISBN 0-470-99124-0, Winston \& Sons, New York, 1977.

Vandaele, A.-C., Hermans, C., Simon, P. C., Carleer, M., Colin, R., Fally, S., Merienne, M.-F., Jenouvrier, A., and Coquart, B.: Measurements of the $\mathrm{NO}_{2}$ absorption cross-section from $42000 \mathrm{~cm}^{-1}$ to $10000 \mathrm{~cm}^{-1}(238-1000 \mathrm{~nm})$ at $220 \mathrm{~K}$ and 294 K, J. Quant. Spectrosc. Ra., 59, 171-184, 1998.

Vlemmix, T., Piters, A. J. M., Stammes, P., Wang, P., and Levelt, P. F.: Retrieval of tropospheric $\mathrm{NO}_{2}$ using the MAX-DOAS method combined with relative intensity measurements for aerosol correction, Atmos. Meas. Tech., 3, 1287-1305, doi:10.5194/amt-31287-2010, 2010.

von Glasow, R. and Crutzen, P. J.: Tropospheric halogen chemistry, in: The Atmosphere, edited by: Keeling, R. F., Vol. 4, Treatise on Geochemistry, edited by: Holland, H. D. and Turekian, K. K., Elsevier-Pergamon, Oxford, 21-64, 2003.

Wagner, T. and Platt, U.: Satellite mapping of enhanced BrO concentrations in the troposphere, Nature, 395, 486-490, 00280836, doi:10.1038/26723, 1998.

Wagner, T., Leue, C., Wenig, M., Pfeilsticker, K. and Platt, U.: Spatial and temporal distribution of enhanced boundary layer BrO concentrations measured by the GOME instrument aboard ERS-2, J. Geophys. Res., 106, 24225-24235, 0148-0227, doi:10.1029/2000JD000201, 2001.

Wagner, T., Dix, B., v. Friedeburg, C., Friess, U., Sanghavi, S., Sinreich, R., and Platt, U.: MAX-DOAS $\mathrm{O}_{4}$ measurements: a new technique to derive information on atmospheric aerosols - principles and information content, J. Geophys. Res., 109, D22205, doi:10.1029/2004JD004904, 2004.
Wagner, T., Beirle, S., and Deutschmann, T.: Three-dimensional simulation of the Ring effect in observations of scattered sun light using Monte Carlo radiative transfer models, Atmos. Meas. Tech., 2, 113-124, doi:10.5194/amt-2-113-2009, 2009.

Wagner, T., Deutschmann, T., and Platt, U.: Determination of aerosol properties from MAX-DOAS observations of the Ring effect, Atmos. Meas. Tech., 2, 495-512, doi:10.5194/amt-2-4952009, 2009.

Weidner, F., Bösch, H., Bovensmann, H., Burrows, J. P., Butz, A., Camy-Peyret, C., Dorf, M., Gerilowski, K., Gurlit, W., Platt, U., von Friedeburg, C., Wagner, T., and Pfeilsticker, K.: Balloonborne limb profiling of $\mathrm{UV} / \mathrm{vis}$ skylight radiances, $\mathrm{O}_{3}, \mathrm{NO}_{2}$, and BrO: technical set-up and validation of the method, Atmos. Chem. Phys., 5, 1409-1422, doi:10.5194/acp-5-1409-2005, 2005.

Weinzierl, B., Petzold, A., Esselborn, M.,Wirth, M., Rasp, K., Kandler, K., Schütz, L., Koepke, P., and Fiebig, M.: Airborne measurements of dust layer properties, particle size distribution and mixing state of Saharan dust during SAMUM 2006, Tellus B, 61, 96-117, 2009.

Wilmouth, D. M., Hanisco, T. F., Donahue, N. M., and Anderson, J. G.: Fourier transform ultraviolet spectroscopy of the $\mathrm{A}\left({ }^{2} \pi_{3 / 2}\right) \rightarrow \mathrm{x}\left({ }^{2} \pi_{3 / 2}\right)$ transition of BrO, J. Phys. Chem., 103, 8935-8944, 1999. 